\title{
The long non-coding RNA DKFZp434J0226 regulates the alternative splicing process through phosphorylation of SF3B6 in PDAC
}

Jinglei $\mathrm{Li}^{1 \dagger}$, Hanxing Tong ${ }^{1+}$, Dongping $\mathrm{Li}^{2+}$, Qiuyu Jiang ${ }^{2}$, Yong Zhang ${ }^{1}$, Wenqing Tang ${ }^{2}$, Dayong Jin ${ }^{1}$, She Chen ${ }^{3}$, Xinyu Qin ${ }^{1^{*}}$, Si Zhang ${ }^{3^{*}}$ (1) and Ruyi Xue $2^{2^{*}}$

\begin{abstract}
Background: Long noncoding RNAs (IncRNAs), a type of pervasive genes that regulates various biological processes, are differentially expressed in different types of malignant tumors. The role of IncRNAs in the carcinogenesis of pancreatic ductal adenocarcinoma (PDAC) remains unclear. Here, we investigated the role of the IncRNA DKFZp434J0226 in PDAC.

Methods: Aberrantly expressed mRNAs and IncRNAs among six PDAC and paired non-tumorous tissues were profiled using microarray analysis. Quantitative real-time polymerase chain reaction was used to evaluate DKFZp434J0226 expression in PDAC tissues. CCK-8 assay, wound-healing assay, soft agar colony formation assay, and transwell assay were performed to assess the invasiveness and proliferation of PDAC cells. Furthermore, RNA pull-down, immunofluorescence, RNA immunoprecipitation, and western blotting assays were performed to investigate the association between DKFZp434J0226 and SF3B6. Tumor xenografts in mice were used to test for tumor formation in vivo.

Results: In our study, 222 mRNAs and 128 IncRNAs were aberrantly expressed ( $\geq$ twofold change). Of these, 66 mRNAs and 53 IncRNAs were upregulated, while 75 IncRNAs and 156 mRNAs were downregulated. KEGG pathway analysis and the Gene ontology category indicated that these genes were associated with the regulation of mRNA alternative splicing and metabolic balance. Clinical analyses revealed that overexpression of DKFZp434J0226 was associated with worse tumor grading, frequent perineural invasion, advanced tumor-node-metastasis stage, and decreased overall survival and time to progression. Functional assays demonstrated that DKFZp434J0226 promoted PDAC cell migration, invasion, and growth in vitro and accelerated tumor proliferation in vivo. Mechanistically, DKFZp434J0226 interacted with the splicing factor SF3B6 and promoted its phosphorylation, which further regulated the alternative splicing of pre-mRNA.
\end{abstract}

\footnotetext{
*Correspondence: qin.xinyu@zs-hospital.sh.cn; zhangsi@fudan.edu.cn; xue. ruyi@zs-hospital.sh.cn

${ }^{\dagger}$ Jinglei Li, Hanxing Tong and Dongping Li contributed equally to this work

${ }^{1}$ Department of General Surgery, Zhongshan Hospital, Fudan University, 180 FengLin Road, Shanghai 200032, China

2 Department of Gastroenterology and Hepatology, Zhongshan Hospital,

Shanghai Institute of Liver Disease, Fudan University, 180 FengLin Road,

Shanghai 200032, China

${ }^{3} \mathrm{NHC}$ Key Laboratory of Glycoconjugate Research, Department

of Biochemistry and Molecular Biology, School of Basic Medical Sciences,

Shanghai Medical College, Fudan University, 130 DongAn Road,

Shanghai 200032, China
}

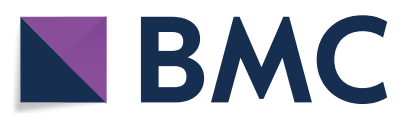

(c) The Author(s) 2021. Open Access This article is licensed under a Creative Commons Attribution 4.0 International License, which permits use, sharing, adaptation, distribution and reproduction in any medium or format, as long as you give appropriate credit to the original author(s) and the source, provide a link to the Creative Commons licence, and indicate if changes were made. The images or other third party material in this article are included in the article's Creative Commons licence, unless indicated otherwise in a credit line to the material. If material is not included in the article's Creative Commons licence and your intended use is not permitted by statutory regulation or exceeds the permitted use, you will need to obtain permission directly from the copyright holder. To view a copy of this licence, visit http://creativecommons.org/licenses/by/4.0/. 
Conclusions: This study indicates that DKFZp434J0226 regulates alternative splicing through phosphorylation of SF3B6 in PDAC and leads to an oncogenic phenotype in PDAC.

Keywords: DKFZp434J0226, LncRNA expression signature, Microarray, Pancreatic ductal adenocarcinoma

\section{Introduction}

Pancreatic cancer is considered a rare type of cancer, with an estimated 57,600 newly diagnosed patients in 2020 in the United States according to the American Cancer Society, accounting for 3.2\% (57,600 of 18,06,590) of all cancer cases (Siegel et al. 2020). Although the incidence rate of most cancers has been decreasing recently, the incidence and mortality rates of pancreatic cancer are gradually increasing (Simard et al. 2014). As the most common pancreatic malignant tumor, pancreatic ductal adenocarcinoma (PDAC) accounts for more than $85 \%$ of pancreatic cancer cases (Li et al. 2004). After diagnosis, only approximately $35 \%$ of the patients survive for $>5$ years (Li et al. 2004). Surgical resection is the only available treatment for PDAC. However, only less than $20 \%$ of tumors can be surgically removed at diagnosis. In addition, these patients usually respond poorly to chemotherapy. Thus, it is necessary to determine the molecular mechanisms underlying PDAC development.

A recent study has reported that epigenetic alterations influence the regulation of gene function in pancreatic cancers (Omura et al. 2009). Non-coding RNAs (ncRNAs), DNA methylation, and histone modifications are the main causes of epigenetic dysregulation. Most mammalian transcriptome is composed of abundant ncRNAs (Ponting et al. 2009), which can be generally divided into long ncRNAs (lncRNAs; $200 \mathrm{nt}$ to $>100 \mathrm{~kb}$ ) and small (18-200 nt). Furthermore, lncRNAs have complex biological functions in multiple processes (Wang et al. 2011). Increasing evidence has shown that lncRNAs have a vital effect on oncogenesis in human cancers (Ponting et al. 2009). Aberrant expression of lncRNAs in different types of human malignant tumors has been widely documented (Wapinski et al. 2011; Gibb et al. 2011), promoting a common interest in the use of therapeutic targets and biomarkers such as MALAT-1 in non-small cell lung carcinoma, HOTAIR in breast cancer, and HEIH in hepatocarcinoma (Schmidt et al. 2011; Gupta et al. 2010; Yang et al. 2011).

Studies have reported that ncRNAs may regulate the process of precursor mRNA (pre-mRNA) splicing. $\mathrm{Hu}$ et al. (2016) discovered that ncRNAs can regulate gene expression through h5S-OT lncRNA during transcription and pre-mRNA splicing. They identified the splicing regulator U2AF65 as a cofactor of the h5S-OT-dependent alternative splicing pathway. U2AF65 is a core splicing regulator required for the binding of U2 snRNP to the pre-mRNA branch site and is essential for splicing machinery and intron excision. In addition, Tripathi et al. (2010) reported that the lncRNA MALAT1 can influence the distribution of splicing factors in nuclear speckles. In addition, they reported that depletion of MALAT1 can change the splicing pattern of similar endogenous pre-mRNAs by regulating the phosphorylated forms of splicing factors (Tripathi et al. 2010), indicating that phosphorylation of splicing factors may be an essential process in the activation of the spliceosome.

Alternative splicing of pre-mRNAs contributes to the diversification of human transcripts and gene functions. Changes in the phosphorylation of splicing factors can regulate alternative splicing patterns in pre-mRNAs. The regulation of alternative splicing patterns is generally considered to be associated with tumor progression, metastatic dissemination, and survival in patients with PDAC. However, the molecular mechanism underlying the activation and regulation of splicing factors in PDAC remains unclear.

In the present study, we detected lncRNA expression patterns in six pairs of PDAC tumor tissue samples and matched non-tumor tissue samples by microarray and in 109 pairs of PDAC tumor samples and non-tumor tissue samples by quantitative real-time polymerase chain reaction (RT-qPCR). We identified DKFZp434J0226 as a potential therapeutic target for PDAC. In addition, DKFZp434J0226 was found to contribute to the phosphorylation of the splicing factor SF3B6, which further regulates the alternative splicing of pre-mRNA.

\section{Materials and methods}

\section{Ethics statement}

Ethical approval for human subjects was obtained from the research ethics committee of Zhongshan Hospital (Y2015-057), and written informed consent was obtained from each patient.

\section{Patient samples and cell lines}

Six paired tumor samples and non-tumor samples from patients with PDAC were randomly obtained from six patients who underwent surgical resection at Zhongshan Hospital, Fudan University, in 2016. Paired PDAC tumor samples and adjacent liver tissue samples were collected from 61 patients (Zhongshan Hospital, 20152019) for RT-qPCR analysis. For the clinical significance study, PDAC tissues were collected from 109 patients 
(Zhongshan Hospital, 2015-2019). The pancreatic cancer cell lines AsPC-1, SW1990, MIAPaCa-2, CFPAC1, Capan-1, and PANC-1 were purchased from the Cell Bank of Type Culture Collection of the Chinese Academy of Sciences (Shanghai Institute of Cell Biology, Chinese Academy of Sciences) and cultured in Dulbecco's modified Eagle's medium (DMEM; Invitrogen, CA, USA) supplemented with $10 \mathrm{U} / \mathrm{mL}$ penicillin $\mathrm{G}$ (Gibco, MA, USA), $10 \mathrm{U} / \mathrm{mL}$ streptomycin, and $10 \%$ fetal calf serum (Gibco, MA, USA). The cells were incubated at $37{ }^{\circ} \mathrm{C}$ with $5 \%$ $\mathrm{CO}_{2}$.

\section{RNA extraction}

Total RNA was extracted from pancreatic cancer cells, snap-frozen PDAC samples, and matched normal nontumor tissue samples using TRIzol reagent (Invitrogen) according to the manufacturer's instructions. RNA quality and quantification assurance were assessed by NanoDrop ND-1000, gDNA contamination and RNA integrity test were assessed by denaturing agarose gel electrophoresis.

\section{Microarray and computational analysis}

Samples (six PDAC tissues and six matched non-tumor tissues) were used to synthesize double-stranded cDNA, which was then labeled and hybridized to the Human LncRNA Array v2.0 $(8 \times 60 \mathrm{~K}$, Arraystar, MD, USA). A total of 30,215 coding transcripts and 33,045 lncRNAs were collected from databases such as the Ensembl, UCSC Knowngenes, and RefSEq. After hybridization and washing, the processed array slides were scanned and analyzed using Agilent Scanner G2505C and Agilent Feature Extraction software (version 10.7.3.1), respectively. Subsequent data processing and quantile normalization were performed using the GeneSpring GX v11.5.1 software package (Agilent Technologies, CA, USA).

LncRNAs and mRNAs that were flagged in all six samples as Present or Marginal ("All Targets Value") were chosen for further data analysis after quantile normalization of the raw data. Differentially expressed mRNAs and lncRNAs with statistical significance within the two groups were identified by volcano plot filtering. Gene ontology (GO) analysis and pathway analysis were performed to explore the roles of aberrantly expressed mRNAs in GO terms or biological pathways. The expression patterns of lncRNA and mRNA samples were examined by hierarchical clustering.

\section{Construction of the coding-non-coding gene co-expression network}

The coding-non-coding gene co-expression $(\mathrm{CNC})$ network construction procedures included the following: (i) preprocessing data: taking the median value of the same coding gene with different transcripts to represent gene expression values without special treatment of lncRNA expression value, (ii) screen data: removing the subset of data according to the lists that show the differential expression of lncRNA and mRNA, (iii) calculating the Pearson correlation coefficient and using the $R$ value to calculate the correlation coefficient of PCC between lncRNA coding genes, and (iv) screening by the Pearson correlation coefficient and selecting the part for which PCC $\geq 0.90$ is considered meaningful and draw the CNC network using Cytoscape.

\section{RT-qPCR}

LncRNA and mRNA expression in PDAC tissues and cells was examined by RT-qPCR using SYBR Premix Ex Taq (Takara, Kusatsu, Japan) on an Eppendorf instrument. Additional file 1: Table S1 shows the primers used in this study. All experiments were performed in triplicates. All samples were normalized to GAPDH. Significance was examined by obtaining the average of the GAPDH-normalized $2^{-\Delta \Delta \mathrm{Ct}}$ values.

\section{LncRNA in situ hybridization}

A biotin-labeled antisense DKFZp434J0226 probe (ATG TTCAGAGAAGACTGGTT) was synthesized using EXIQON. The paraffin-embedded tissues were treated with a peroxidase-quenching solution and incubated with a biotin-labeled probe. Then, streptavidin-horseradish peroxidase was reacted with the bound biotin-labeled probe. A TSA amplification kit (Perkin Elmer, Waltham, USA) was used to amplify the signal.

\section{RNA pull-down}

We performed an RNA pull-down assay as previously described (Zhang et al. 2017). Briefly, biotin-labeled RNA was synthesized using in vitro transcription, in which T7 RNA polymerase was used with biotin-UTP. A forward primer (TAATACGACTCACTATAGGG) involving T7 RNA polymerase promoter and a reverse primer (GAT TTAGGTGACACTATAG) involving the T3 RNA polymerase promoter were used to amplify the PCR fragments. In vitro transcription was performed using PCR products as DNA templates. Biotinylated RNA probes (approximately $20 \mathrm{pmol}$ ) were incubated with cell lysates for $30 \mathrm{~min}$. Streptavidin Sepharose High-Performance beads (GE Healthcare, PA, USA) were used to isolate RNA-protein complexes. Liquid chromatography-mass spectrometry (LC-MS) was used to detect the isolated proteins.

\section{RNA immunoprecipitation}

RNA immunoprecipitation was performed as previously described (Zhang et al. 2017) Briefly, UV-cross-linking 
of living cells $\left(1 \times 10^{6}\right)$ was performed at $254 \mathrm{~nm}(2000 \mathrm{~J} /$ $\mathrm{m}^{2}$ ). Cells were washed with cold phosphate-buffered saline (PBS) and then lysed in $300 \mu \mathrm{L}$ of lysis buffer (200 U/mL RNase inhibitor; Thermo Fisher, MA, USA), $0.5 \% \mathrm{C} 24 \mathrm{H} 39 \mathrm{O} 4 \mathrm{Na}, 0.5 \% \mathrm{NP} 40$, and protein inhibitor (Thermo Fisher) for $1 \mathrm{~h}$. After treatment with DNase I (NEB, MA, USA) for $20 \mathrm{~min}$, the cell lysate was incubated with anti-P14 antibody or IgG (Sigma) overnight at $4{ }^{\circ} \mathrm{C}$. Then, $50 \mu \mathrm{L}$ of protein A/G agarose beads (Santa Cruz, CA, USA) were added to the cell lysate. RNA binding with SF3B6 was recovered using Trizol-chloroform and detected using qPCR.

\section{Construction of cell lines with knockdown or overexpressed DKFZp434J0226}

To knock down DKFZp434J0226, $50 \mathrm{nM} \mathrm{DKFZp434J-}$ 0226siRNA (SI05138511, si 1\# and SI05138518, si 2\#, Qiagen, Hilden, Germany) was transfected into MIAPaCa-2 cells and PANC-1 cells using Lipofectamine 2000 reagent, according to the manufacturer's instructions (Wei et al. 2008). Control groups were transfected with the transfection agent, but not siRNA (mock) or scrambled control siRNA (negative control). To clone the full-lengthDKFZp434J0226, PCR was performed with primers 5'-CGGAATTCGCCTTGGTGTTCAAGAAGA TTCCAG- $3^{\prime}$ and $5^{\prime}$-CGGAATTCTTTATTCTTACTA CATAAGATCCAC-3'. Full-length DKFZp434J0226 was subcloned into the pLVX-IRES-Puro lentiviral expression vector (Clontech, CA, USA). pLVX-IRES-PuroDKFZp434J0226 or pLVX-IRES-Puro Packaging psPAX2 and envelope pMD2.G vectors were co-transfected into HEK 293T cells. Lentivirus-containing medium was collected from HEK 293T cells and filtered. In the presence of $8 \mu \mathrm{g} / \mathrm{mL}$ polybrene, AsPC-1 cells and CFPAC- 1 cells were infected with the enveloped lentivirus. Stable cell lines were selected using puromycin $(10 \mu \mathrm{g} / \mathrm{mL})$. For the knockdown of SF3B6, 50 nM SF3B6 siRNA (AM16708, Thermo Fisher) was transfected into AsPC-1 cells.

\section{Cell proliferation assay}

Cell proliferation was measured using cell counting kit-8 (Dojindo Co., Kumamoto, Japan) according to the manufacturer's protocol. Cells were incubated with CCK-8 for $1 \mathrm{~h}$ in triplicate. We assessed the cell proliferation rate by measuring the absorbance at $450 \mathrm{~nm}$ using a universal microplate reader. Four biological replicates were analyzed.

\section{Colony formation assay}

Soft agar colony formation assay was performed to measure the anchorage-independent growth ability as described previously (Liu et al. 2013). A total of $1 \times 10^{3}$ cells per well were suspended in DMEM containing $0.3 \%$ noble agarose (Takara) in six-well plates. The suspension was laid over DMEM containing 0.6\% noble agarose and further overlaid with DMEM. After replenishing the medium every other day, the plates were incubated for 14 days in a $5 \% \mathrm{CO}_{2}$ incubator at $37^{\circ} \mathrm{C}$. A Nikon ECLIPSE TE300 microscope was used to image the colonies. Four biological replicates were analyzed.

\section{Cell migration and invasion assays}

Cell migration capacity was measured by a cell migration (wound-healing) assay, as described previously (Bao et al. 2012). Cells were seeded in a six-well plate and incubated at $37{ }^{\circ} \mathrm{C}$ until they reached $90 \%$ confluence. The confluent cells were then scratched with a $200 \mathrm{~mL}$ pipette tip and washed with PBS, followed by incubation with Mag in complete medium. After $24 \mathrm{~h}$ of incubation, the cells were fixed and stained with $2 \%$ ethanol containing $0.2 \%$ crystal violet powder (15 min), and randomly chosen fields were photographed under a light microscope. The number of cells that migrated into the scratched area was calculated. Cell invasive potential was studied by calculating the number of cells that invaded through Matrigel-coated transwell polycarbonate membrane inserts as described previously (Verma et al. 2006). In brief, transwell inserts with a pore size of $12 \mathrm{Am}$ were coated with $0.78 \mathrm{mg} /$ $\mathrm{mL}$ Matrigel in serum-free medium. Cells were recovered by trypsinization, washed, and resuspended in a serum-free medium. Then, $0.5 \mathrm{~mL}$ of the cell suspension $\left(0.5 \times 10^{6}\right.$ cells $)$ was added to duplicate wells. After incubation for $48 \mathrm{~h}$, the cells that passed through the filter were stained using the Hema-3 stain kit (Fisher Scientific, Houston, TX, USA). The cells in 10 random fields were counted under a microscope. Both assays were performed in four biological replicates.

\section{Subcellular fractionation}

Cells were resuspended in harvest buffer $(10 \mathrm{mM}$ HEPES [pH 7.9], $50 \mathrm{mM} \mathrm{NaCl}, 0.5 \mathrm{M}$ sucrose, $0.1 \mathrm{mM}$ EDTA, $0.5 \%$ Triton-100, phosphatase inhibitors, and PMSF) and incubated on ice for $10 \mathrm{~min}$. Nuclei were obtained by centrifugation at $12,000 \mathrm{rpm}$ for $10 \mathrm{~min}$ at $4{ }^{\circ} \mathrm{C}$. Nuclei were washed three times with harvest buffer and dissolved in $1 \times$ loading buffer. The supernatant containing the cytosolic extract was also collected and dissolved in $5 \times$ loading buffer. The cytoplasmic and nuclear fractions were analyzed by sodium dodecyl sulphate-polyacrylamide gel electrophoresis (SDS-PAGE). The validity of fractionation was detected by western blotting using LaminB as 
the nuclear protein control and $\beta$-tubulin as the cytosolic protein control.

\section{Co-immunoprecipitation and western blotting}

Cells were lysed with lysis buffer $(50 \mathrm{mM}$ Tris- $\mathrm{HCl} \mathrm{pH}$ 7.4, $150 \mathrm{mM} \mathrm{NaCl}, 1 \mathrm{mM} \mathrm{NaF}, 1 \% \mathrm{NP}-40,1 \mathrm{mM}$ EDTA, and $1 \times$ protease and phosphatase inhibitor solution) on ice for $30 \mathrm{~min}$. Protein A/G agarose beads were used to pre-clear the supernatants. Anti-SF3B6 antibody (dilution: 1:500; Catalog number PA5-57077, Thermo Scientific, USA) was used for immunoprecipitation. The mixture was incubated with protein A/G-agarose beads (Santa Cruz Biotechnology) overnight on a mechanical shaker at $4{ }^{\circ} \mathrm{C}$. The beads were harvested and rinsed three times with a lysis buffer. Immunoblotting was used to detect bead-captured SF3B6. Proteins were separated by $10 \%$ SDS-PAGE and electrophoretically transferred to a polyvinylidene difluoride membrane (Millipore, MA, USA). The membrane was incubated with the indicated antibody at $4{ }^{\circ} \mathrm{C}$ overnight after blocking with $5 \%$ non-fat dry milk. An enhanced chemiluminescence kit (Tiangen, Beijing, China) was used to develop the blots. Primary antibodies against P-tyrosine (dilution: 1:500; Catalog number sc-207232, Santa Cruz), SF3B6 (dilution: 1:500; Catalog number ARG40015, Arigo Biolaboratories, Taiwan, China), proliferating cell nuclear antigen PCNA, (dilution: 1:2000; Catalog number sc-56, Santa Cruz), GAPDH (dilution: 1:1000; Catalog number sc-47724, Santa Cruz), LaminB (dilution: 1:500; Catalog number ab32535, Abcam, Cambridge, MA), and $\beta$-tubulin (dilution: 1:500; Catalog number ab6046, Abcam, Cambridge, MA) were used as indicated. Each western blotting assay was replicated three times.

\section{Immunofluorescence}

Cells were incubated on glass coverslips pre-coated with poly-l-lysine, fixed with $4 \%$ paraformaldehyde, permeabilized with $0.2 \%$ Triton X-100, and blocked in $10 \%$ bovine serum albumin in PBST for $30 \mathrm{~min}$ at $25^{\circ} \mathrm{C}$. After staining with secondary antibodies, the primary antibodies were incubated at $4{ }^{\circ} \mathrm{C}$ overnight. Primary antibodies against SF3B6 (dilution: 1:500; Catalog number PA557077, Thermo Scientific, USA) and DAPI (Beyotime, Shanghai, China) were used to identify SF3B6 and cell nuclei. A Leica confocal microscope (Leica TCS SP8, Germany) was used to capture the images.

\section{Animal studies}

Animal studies were approved by the Animal Use Committee at Fudan University. Four-week-old female $\mathrm{BALB} / \mathrm{c}$ nude mice were obtained from the Experimental Animal Center of Fudan University. Animals were housed with a 12-h light/dark cycle, and MiaPaCa-2 cells infected with control lentivirus and DKFZp434J0226 lentivirus $\left(2 \times 10^{6}\right.$ viable cells/mouse) were resuspended in PBS $(0.1 \mathrm{~mL})$ and injected subcutaneously into the right dorsal flank of BALB/c-nu/nu mice. After the tumor volume reached $200 \mathrm{~mm}^{3}$, control group $(\mathrm{n}=6)$ and DKFZp434J0226 overexpressed group $(\mathrm{n}=7)$ were analyzed. The tumor volume was calculated as

$$
\mathrm{V}\left(\mathrm{mm}^{3}\right)=\left(\mathrm{ab}^{2}\right) / 2,
$$

where "a" indicates the tumor length and " $\mathrm{b}$ " indicates the tumor width. The mice were anesthetized by intraperitoneal administration of pentobarbital $(75 \mathrm{mg} / \mathrm{kg}$ ) and tumors were harvested by surgery once tumor size reached $1200 \mathrm{~mm}^{3}$. Tumors were measured every 3-4 days. Mice bearing large tumors were carefully monitored for any signs of discomfort.

\section{Statistical analysis}

Statistical analyses were performed using GraphPad Prism 5.0 software (GraphPad Prism Software Inc., San Diego, CA). Unpaired Student's t-test or the MannWhitney $\mathrm{U}$ test was used for comparing two groups. Paired data were compared using a paired t-test. Analysis of variance (ANOVA) was used to compare three or more groups. Ordinary one-way ANOVA with the Sidak test was used for multiple comparisons between different groups. Categorical variables were compared using the $\chi^{2}$ test. Independent two-sample $\mathrm{t}$-tests were used to compare continuous variables. Univariate and multivariate analyses were performed using the Cox proportional hazards model. Survival curves were obtained using the Kaplan-Meier method with the log-rank test. Data are presented as mean \pm standard deviation $(\mathrm{SD})$ of three independent experiments. All tests were two tailed, and a $P$-value of $<0.05$ was considered statistically significant.

\section{Results \\ LncRNA expression profile in PDAC}

Systematic variations in the expression of lncRNAs between six PDAC samples and paired non-tumor samples were demonstrated by hierarchical clustering (Fig. 1A). Additional file 1: Table S2 shows the clinical characteristics of the patients. The expression levels of lncRNAs in paired samples were clearly shown by calculating the log fold change Tumor/Normal $(\mathrm{T} / \mathrm{N})$. We identified 128 aberrantly expressed lncRNAs ( $\geq$ twofold, $P<0.05)$ in RefSeq_NR, Fantom, lncRNA, UCR Ensembl, misc_lncRNA, Fantom_stringent, UCSC_knowngene, $\mathrm{H}$-invDB, NRED, and RNAdb, with 53 upregulated lncRNAs and 75 downregulated lncRNAs (Fig. 1B and Additional file 1: Table S3). 


\section{A}

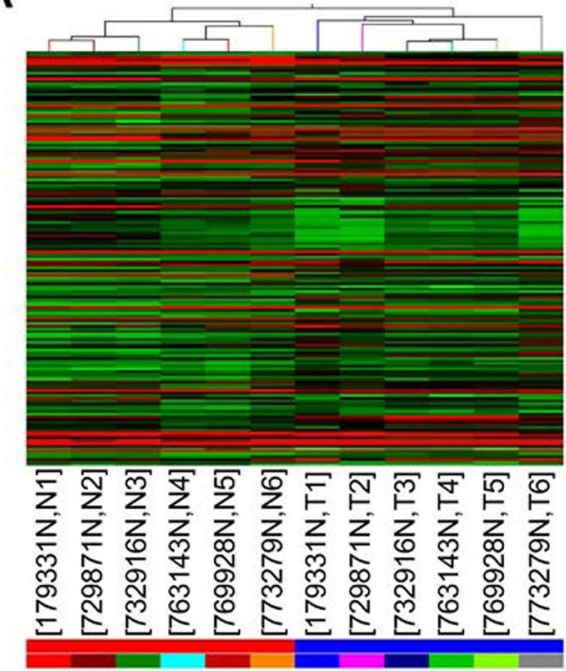

Nontumor PDAC
B

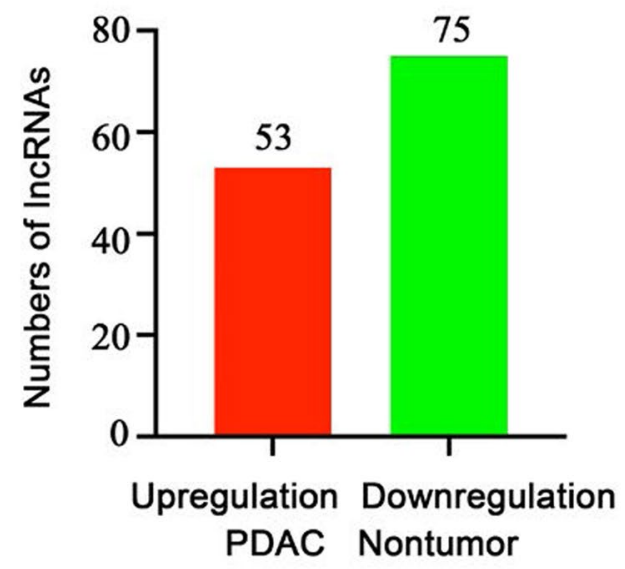

D

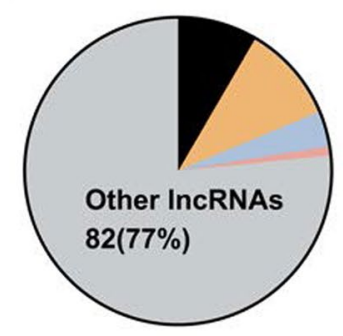

- Enhancer IncRNAs $9(8 \%)$

$\square$ Rinn lincRNAs 11(10\%) $\square$ HOX IncRNAs $4(4 \%)$ $\square$ LncRNAs nearby coding gene $1(1 \%)$ $\square$ Other IncRNAs 82(77\%)

Fig. 1 Microarray analysis of differentially expressed IncRNAs between six pancreatic ductal adenocarcinoma $(T)$ samples and paired non-tumor (N) samples. A Hierarchical cluster analysis of differentially expressed ( $\geq$ twofold change) IncRNAs between six pancreatic ductal adenocarcinoma ( $\mathrm{T}$ ) samples and paired nontumor $(\mathrm{N})$ samples. The red color indicates upregulation, while the green color indicates downregulation. B A total of 128 IncRNAs, with the upregulation of 53 IncRNAs and downregulation of 75 IncRNAs, were selected for clustering. C Classifications of detected IncRNAs in pancreatic ductal adenocarcinoma samples. D Classifications of significantly differentially expressed IncRNAs between pancreatic ductal adenocarcinoma samples and paired nontumor samples

LncRNAs were classified as Enhancer lncRNAs, Rinn lincRNAs, HOX lncRNAs, and LincRNAs nearby coding genes (Ørom et al. 2010; Rinn et al. 2007). Human Homeobox transcription factor (HOX) clusters have been found to contribute to the formation of numerous lncRNAs (Rinn et al. 2007). The lncRNAs expressed in site-specific fashion may have a general regulating ability as the HOX and used similar enhancers as HOX genes. In our study, approximately 281 HOX lncRNAs were detected, four of which were aberrantly expressed in human HOX loci in PDAC (Additional file 1: Table S4). Eleven of the 2341 lncRNAs were found to be aberrantly expressed, and the profiling data of Rinn lncRNAs are provided in Additional file 1: Table S5. Nine of the $1 \mathrm{~m} 133$ enhancer lncRNAs were detected with different expressions, and the profiling data are shown in Additional file 1: Table S6. However, we did not find any enhancer lncRNAs nearby coding genes (distance, $300 \mathrm{~kb}$ ), except for one lncRNA (distance, $300 \mathrm{~kb}$; lncRNA-AK000839 and coding gene-NM_001075099). The classification of the detected lncRNAs and differentially expressed lncRNAs in paired samples is summarized in Fig. 1C, D, respectively.

\section{Overview of mRNA profiles}

Systematic variations in the expression of protein-coding mRNAs in the six PDAC samples and paired non-tumor tissues are shown by hierarchical clustering (Fig. 2A). A 
A
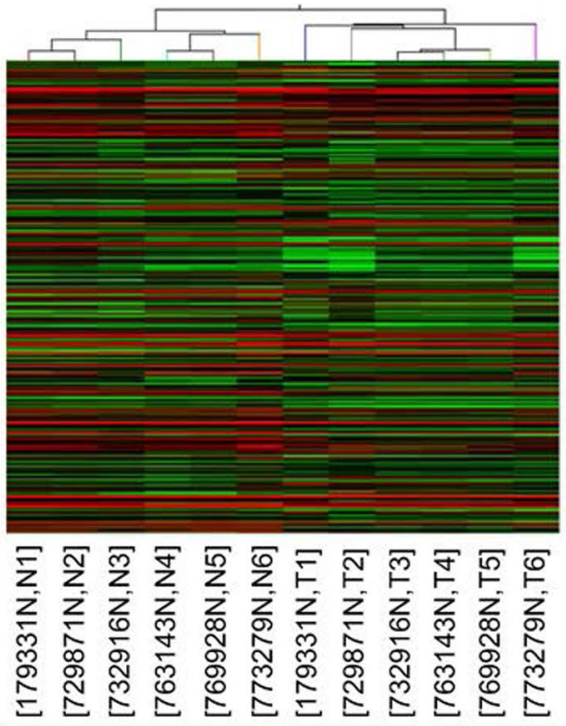

Nontumor PDAC
B

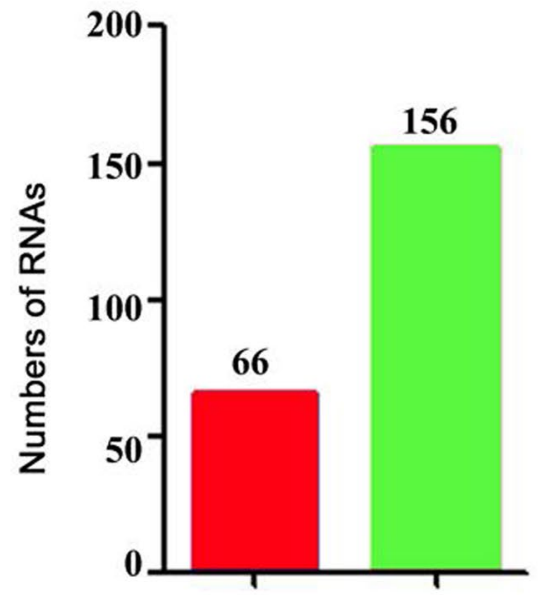

Upregulation Downregulation

C

Sig pathway of DE gene (upregulated)

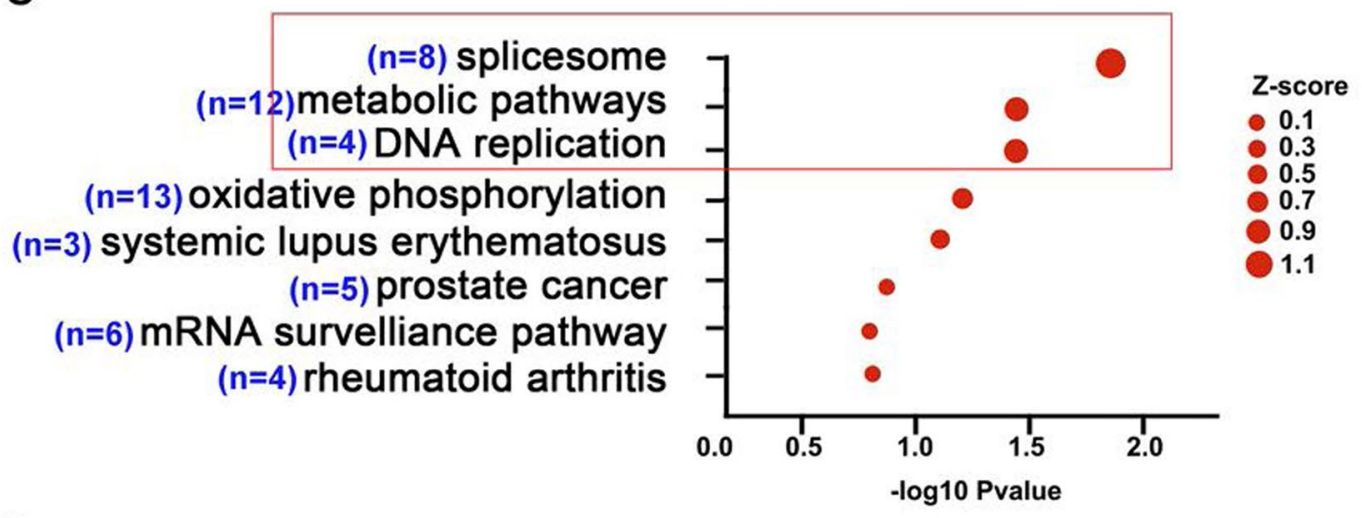

D

Sig pathway of DE gene (downregulated)

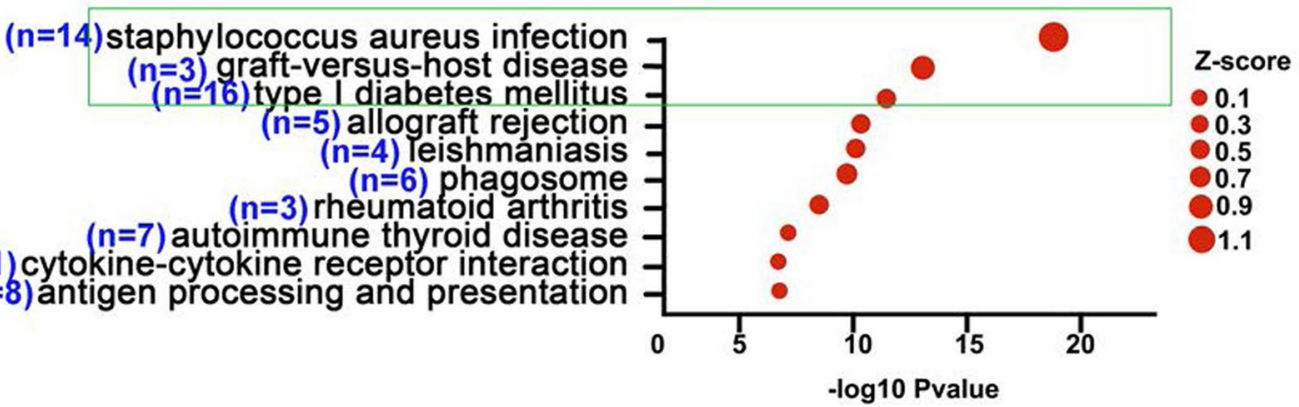

Fig. 2 Microarray analysis of differentially expressed mRNAs between six pancreatic ductal adenocarcinoma (T) samples and paired non-tumor (N) samples. A Hierarchical cluster analysis of differentially expressed ( $\geq$ twofold change) mRNAs between six pancreatic ductal adenocarcinoma (T) samples and paired non-tumor (N) samples. The red color indicates upregulation, while the green color indicates downregulation. B A total of 222 mRNAs, with the upregulation of 66 mRNAs and downregulation of 156 mRNAs, were selected for clustering. $\mathbf{C}$ Gene ontology analysis of the differentially expressed genes (DE) between six PDAC tumors and paired non-tumor samples. The upregulated mRNAs are mainly aggregated in (a) the "spliceosome," (b) "metabolic pathway," and (c) "glycosaminoglycan and keratan sulfate" (framed in red). The downregulated mRNAs mainly associated with (d) "Staphylococcus aureus infection," (e) "graft-versus-host disease," and (f) "type I diabetes mellitus" (framed in green) 
total of 222 mRNAs were differentially expressed among the six pairs of samples, with the upregulation of 66 mRNAs and downregulation of 156 mRNAs in PDAC compared to that in the corresponding normal samples (Fig. 2B and Additional file 1: Table S7). GO analysis indicated the upregulated mRNAs were mostly aggregated in the "spliceosome," the "metabolic pathway," and "glycosaminoglycan and keratan sulfate" (Fig. 2C), and the downregulated mRNAs were mainly associated with "Staphylococcus aureus infection," "graft-versus-host disease," and "type I diabetes mellitus" (Fig. 2D).

\section{DKFZp434J0226 can be an independent prognostic factor in patients with PDAC}

We investigated the relationship between DKFZp434J0226 (one with the greatest changes in expression) and the protein-coding genes using an absolute correlation coefficient cutoff of $>0.85$ and an FRD of $<0.1$. We found that hundreds of coding genes involved in cancer growth and metastasis were significantly associated with the IncRNA DKFZp434J0226 (Fig. 3A). We further examined the expression of DKFZp434J0226 in 109 pairs of PDAC and corresponding non-tumor tissue samples using RT-qPCR. Our data confirmed that DKFZp434J0226 was overexpressed in PDAC tissues compared to non-tumor tissues (Fig. 3B). Additionally, similar expression patterns were observed in the six PDAC cell lines compared to the immortal human pancreatic ductal epithelial (HPDE) cell line (Fig. 3C). Thus, our data demonstrated a strong consistency between the microarray data and qPCR results.

In the CNC network, DKFZp434J0226 was connected to a variety of protein-coding genes involved in cancer metastasis and growth (Fig. 3A). Therefore, we studied the role of the IncRNA DKFZp434J0226 in PDAC. In situ hybridization confirmed that the expression of DKFZp434J0226 was increased in PDAC tissues and was localized in both the nucleus and cytoplasm (Fig. 3D). We further examined the association between DKFZp434J0226 expression and clinical characteristics of 109 PDAC tissue samples from patients. Additional file 1: Table S8 presents the clinical characteristics of the patients. Clinicopathological analysis showed that high DKFZp434J0226 levels in PDAC tissues were significantly correlated with tumor grade, perineural invasion, and tumor-node-metastasis (TNM) stage. However, DKFZp434J0226 levels failed to match other clinicopathological data (Additional file 1: Table S9). Kaplan-Meier curves showed that high DKFZp434J0226 expression in tumor samples was positively correlated with shorter overall survival (OS) and time to progression (TTP) $(P=0.003$ and $P=0.002$, respectively; Fig. 3E). Univariate analysis indicated that high DKFZp434J0226 expression was correlated with both OS $(P=0.002)$ and TTP $(P=0.003)$. In addition, other factors indicative of shorter OS was tumor grading, tumor size, perineural invasion, vascular invasion, lymph node metastasis, and TNM stage. The factors associated with lymph node metastasis, tumor grading, vascular invasion, and TTP included age, tumor size, perineural invasion, and TNM stage, as shown in Additional file 1: Table S10. Multivariate analyses revealed that high DKFZp434J0226 levels were independently associated with worse OS $(P=0.014)$ and higher PDAC recurrence (TTP, $P=0.024$; Table 1 ).

\section{Effect of DKFZp434J0226 on PDAC cell proliferation, invasion, and migration}

To estimate the effect of DKFZp434J0226 on cell biological behaviors, we established MIAPaCa-2 cell line with DKFZp434J0226 knockdown (Fig. 4A) and AsPC-1 cell line with DKFZp434J0226 overexpression (Fig. 4B). Cell growth was inhibited by DKFZp434J0226 knockdown using cell counting kit- 8 assays (Fig. 4C) and elevated by DKFZp434J0226 overexpression (Fig. 4D). Soft agar colony formation assay indicated that the colony formation ability was decreased by DKFZp434J0226 knockdown (Fig. 4E), and increased by DKFZp434J0226 overexpression (Fig. 4F). Consistent with the results of cell proliferation, DKFZp434J0226-knockdown MIAPaCa-2 and PANC-1 cells and DKFZp434J0226-overexpressing AsPC-1 and CFPAC-1 cells showed lower and higher expression of PCNA, respectively, compared to control cells (Fig. 4G). Cell scratch assay demonstrated that the capacity of cells to migrate was attenuated by DKFZp434J0226 knockdown and enhanced by DKFZp434J0226 overexpression (Fig. 4H, I). Transwell invasion assay indicated that the invasiveness of cells was inhibited by DKFZp434J0226 knockdown and

\footnotetext{
(See figure on next page.)

Fig. 3 Increased DKFZp434J0226 (DKFZ) expression is positively associated with poor prognosis of pancreatic ductal adenocarcinoma.

A Coding-non-coding gene co-expression network analysis showing the association between DKFZ and genes involved in cancer growth (framed in red) and metastasis (framed in green). B RT-qPCR analysis showing the increased expression of DKFZ in PDAC compared to that in the corresponding non-tumor tissues $(n=109)$. C RT-qPCR analysis demonstrating the increased expression of DKFZ in six PDAC cell lines (AsPC-1, MIAPaCa-2, PANC-1, SW1990, CFPAC-1, and Capan-1) compared to that in immortal, transformed, human pancreatic ductal epithelial cells. D Typical patterns of DKFZ expression in paired PDAC tissues. Left panel: HE staining of paired PDAC tissue. Right panel: in situ hybridization of DKFZ in paired PDAC tissues. N, adjacent nontumorous tissues; T, tumor tissues. E Kaplan-Meier analysis for OS and TTR according to DKFZ expression (cutoff value: median value) in 109 patients with PDAC. Data are shown as mean $\pm S D ;{ }^{*} P<0.05,{ }^{* *} P<0.01$
} 
A

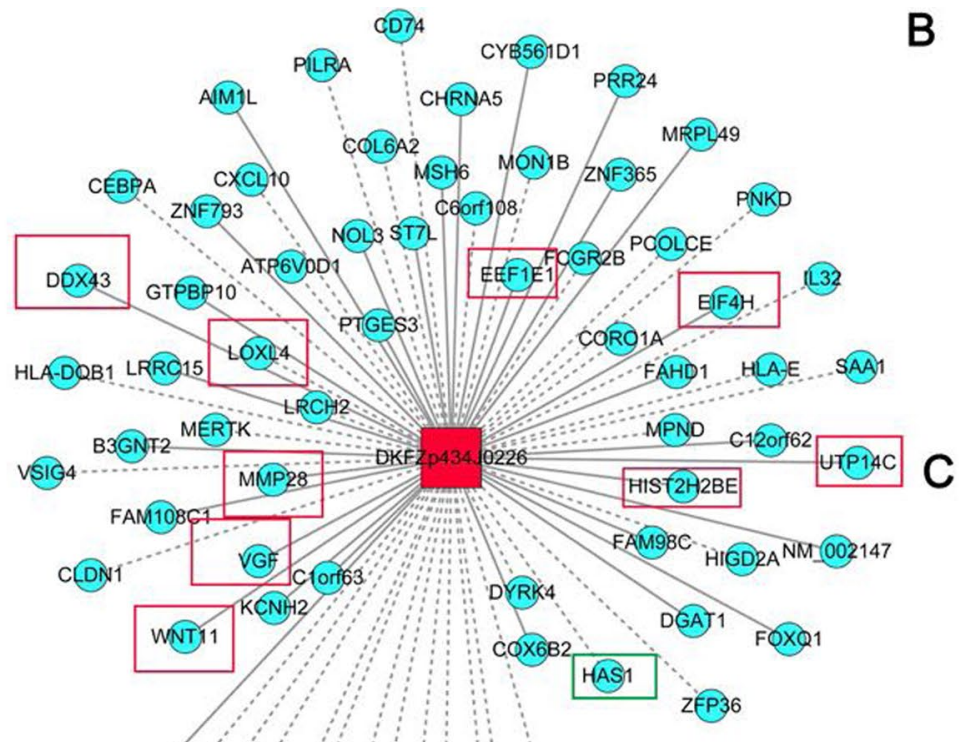

HIST1H1C (S4A7 (BBA VIP) ODAO MS4AGA

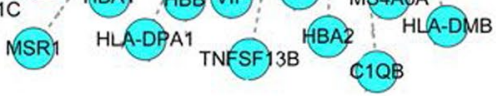

D

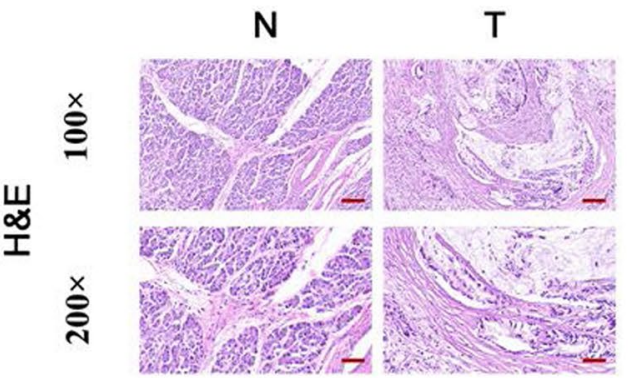

E

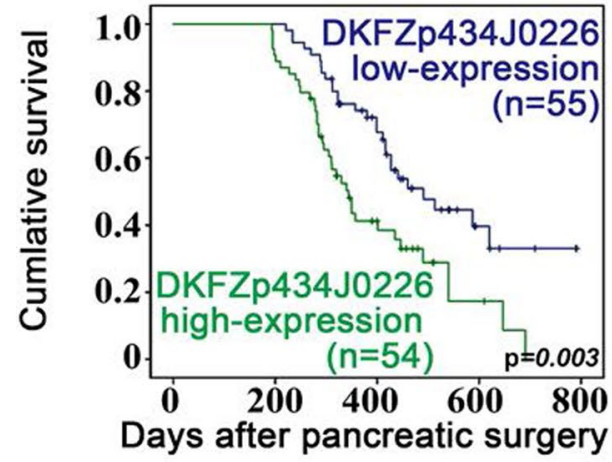

number of patients at risk

$\begin{array}{llllll}\text { low-expression } & 55 & 55 & 42 & 21 & 17 \\ \text { high-expression } & 54 & 48 & 22 & 10 & 0\end{array}$

Fig. 3 (See legend on previous page.)
B
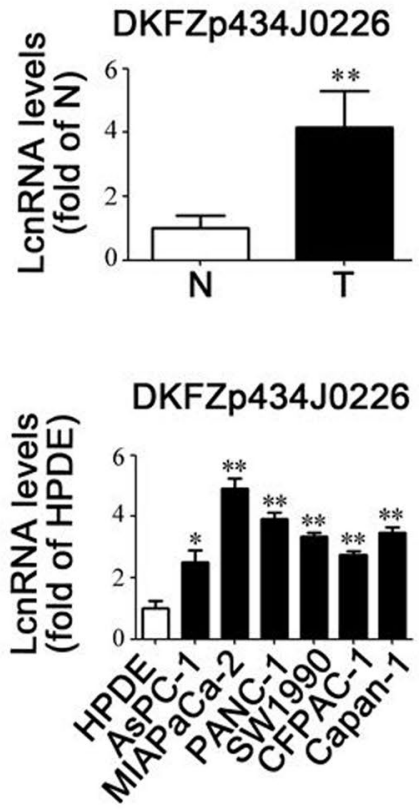

$\begin{array}{ll}N & T\end{array}$
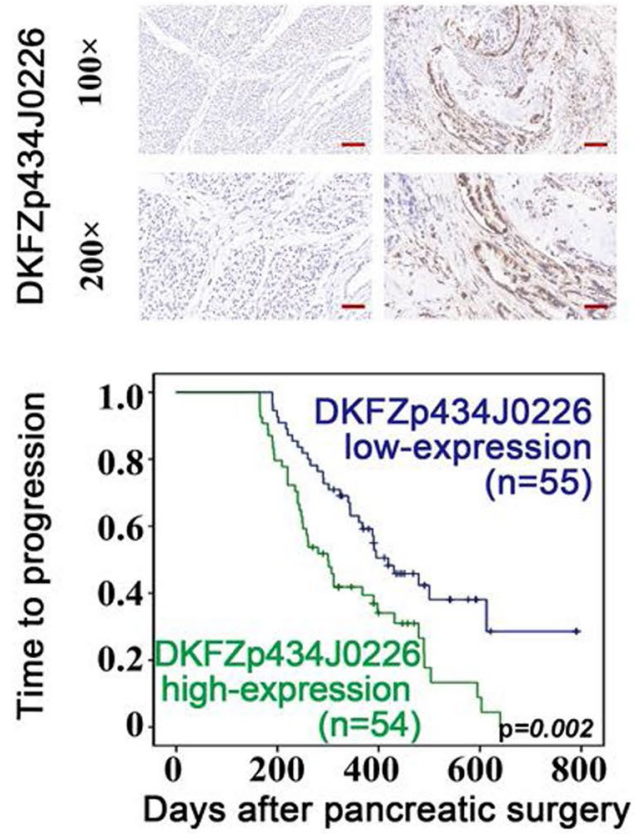

number of patients at risk

$\begin{array}{lrrrrr}\text { low-expression } & 55 & 51 & 27 & 21 & 16 \\ \text { high-expression } & 54 & 44 & 21 & 5 & 0\end{array}$ 
Table 1 Multivariate analyses of factors associated with OS and TTP

\begin{tabular}{|c|c|c|}
\hline & Hazard ratio $(95 \% \mathrm{Cl})$ & $P$ \\
\hline \multicolumn{3}{|l|}{ OS } \\
\hline Tumor differentiation (I vs. || vs. III) & $0.940(0.488-1.811)$ & 0.853 \\
\hline Tumor size (T1 vs. T2 vs. T3) & $1.817(0.668-4.944)$ & 0.243 \\
\hline Lymph node metastasis (negative vs. positive) & $1.263(0.722-2.209)$ & 0.414 \\
\hline Perineural invasion (negative vs. positive) & $0.684(0.336-1.392)$ & 0.295 \\
\hline Vascular invasion (negative vs. positive) & $1.336(0.770-2.318)$ & 0.002 \\
\hline TNM stage (I vs. II) & $1.913(0.470-7.795)$ & 0.365 \\
\hline DKFZp434J0226 expression (low vs. high) & $2.017(1.154-3.527)$ & 0.014 \\
\hline \multicolumn{3}{|l|}{ TTP } \\
\hline Age, years ( $\leq 60$ vs. $>60)$ & $1.523(0.877-2.647)$ & 0.135 \\
\hline Tumor grade (I vs. || vs. |II) & $1.040(0.566-1.912)$ & 0.899 \\
\hline Tumor size (T1 vs. T2 vs. T3) & $1.966(0.812-4.764)$ & 0.134 \\
\hline Lymph node metastasis (negative vs. positive) & $1.481(0.866-2.534)$ & 0.151 \\
\hline Perineural invasion (negative vs. positive) & $0.567(0.289-1.111)$ & 0.098 \\
\hline Vascular invasion (negative vs. positive) & $1.385(0.790-2.428)$ & 0.006 \\
\hline TNM stage (I vs. II) & $1.683(0.474-5.970)$ & 0.421 \\
\hline DKFZp434J0226 expression (low vs. high) & $1.875(1.085-3.237)$ & 0.024 \\
\hline
\end{tabular}

OS overall survival, TTP time to progression

Variables were adopted for prognostic significance using univariate analysis $(P<0.05)$. Bold $P$ values less than 0.05 , indicating statistical significance

promoted by DKFZp434J0226 overexpression (Fig. 4J). The similar effects of DKFZp434J0226 on cell biological behaviors were also observed in PANC-1 cell line with DKFZp434J0226 knockdown and CFPAC-1 cell line with DKFZp434J0226 overexpression (Additional file 2: Fig. S1A-I).

\section{DKFZp434J0226 interacts with the splicing factor SF3B6 and promotes its phosphorylation}

To identify DKFZp434J0226-interacting proteins, we performed native RNA pull-down assay combined with mass spectrometry (RAP-MS) using MIAPaCa-2 cells (Fig. 5A). Mass spectrometry analysis revealed that a 14-KDa protein, SF3B6, interacted with DKFZp434J0226. Western blotting with anti-SF3B6 antibody confirmed that SF3B6 interacted with DKFZp434J0226 (Fig. 5B). In contrast, DKFZp434J0226 was not associated with PCNA protein (a negative control). Cross-linked RIP assays demonstrated an endogenous association between
SF3B6 and DKFZp434J0226 (Fig. 5C). The expression of DKFZp434J0226, but not MEG3 (a negative control), was upregulated in samples immunoprecipitated with antiSF3B6 antibodies compared to that in samples immunoprecipitated with $\lg$. These results demonstrated that the SF3B6 protein can bind to DKFZp434J0226RNA. The splicing pathway in eukaryotes contains the U2- and U12-dependent pathways, splicing-specific pre-mRNA introns differing in the branch point and splice site consensus sequences. SF3B6 is a member of the SF3B spliceosome and is present in the U2- and U12-dependent pathways, responsible for the first catalytic step of the splicing reaction (Yokoi et al. 2011; Will et al. 2001). It has a close contact with branch site $\mathrm{A}$ in the assembled spliceosome, indicating that SF3B6 plays a crucial role in the splicing process (Perea et al. 2016). Next, we examined the protein levels of SF3B6 inDKFZp434J0226 overexpressed and knockdown cells (Fig. 5C). No significant difference in SF3B6 protein levels was observed in

\footnotetext{
(See figure on next page.)

Fig. 4 DKFZp434J0226 (DKFZ) promotes PDAC cell proliferation and migration. A, B Verification of DKFZ knockdown (A) and DKFZ overexpression (B) efficiency in MIAPaCa-2 and AsPC-1 cells $(n=3)$. Data are shown as mean $\pm S D ;{ }^{*} P<0.05,{ }^{* *} P<0.01$. C Cell growth curves of lipofectamine-treated MIAPaCa-2 (Mock) cells, negative siRNA-transfected MIAPaCa-2 (NC) cells, and two DKFZ siRNA-transfected MIAPaCa-2 (si1 and si2; $\mathrm{n}=4$ ). Data are shown as mean $\pm \mathrm{SD} ;{ }^{*} P<0.05$ vs. Mock and NC; ${ }^{*} P<0.01$ vs. Mock and NC. D Cell growth curves of control lentivirus-infected AsPC-1 cells (control) and DKFZ lentivirus-infected AsPC-1 cells (DKFZ) $(n=4)$. Data are shown as mean $\pm S D ;{ }^{*} P<0.05$ vs. Mock and NC; ${ }^{* *} P<0.01$ vs. Mock and NC. E Soft agar colony formation assay and relative levels of colonies in Mock, NC, si1, and si2 cells ( $\left.n=4\right)$. F Soft agar colony formation assay and relative levels of colonies in control and DKFZ cell $(n=4)$. G Western blotting analysis of PCNA expression in Mock, NC, si1 and si2 MIAPaCa-2 cells. Western blotting analysis of PCNA expression in control and overexpression AsPc-1 cells. $\mathbf{H}-\mathbf{J}$ Wound healing $(\mathbf{H}, \mathbf{l})$ and migration $(\mathbf{J})$ assays using the referred PDAC cells. Quantification using Image $(\mathrm{n}=4)$. E-J Data are shown as mean $\pm S D ;{ }^{*} P<0.05,{ }^{* *} P<0.01$. Scale bars refer to $100 \mu \mathrm{m}$
} 


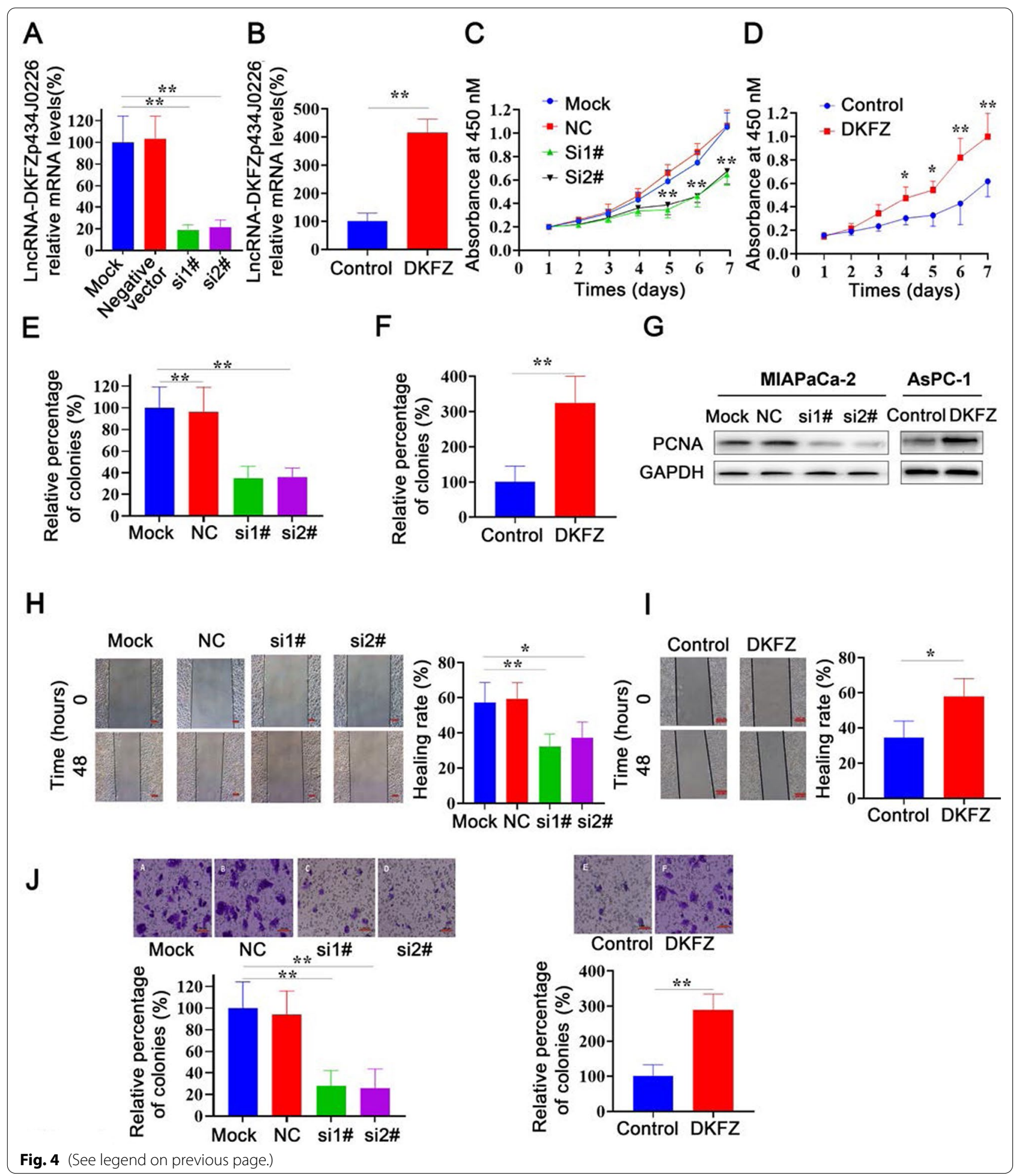


A

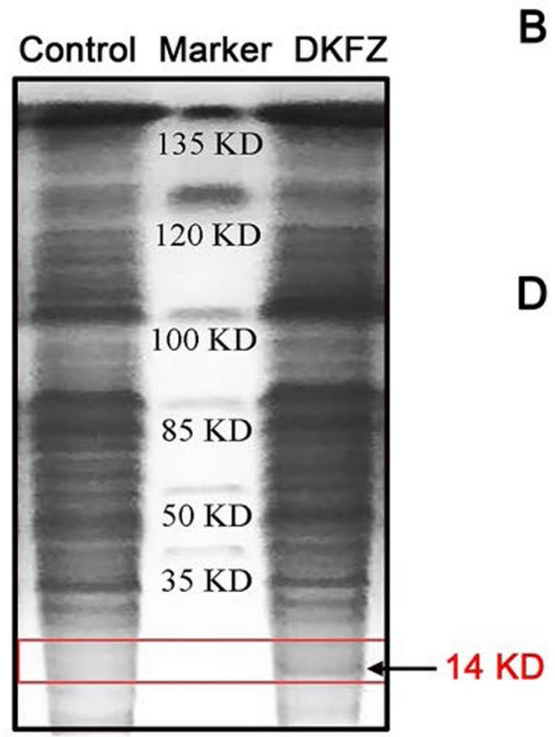

B

D
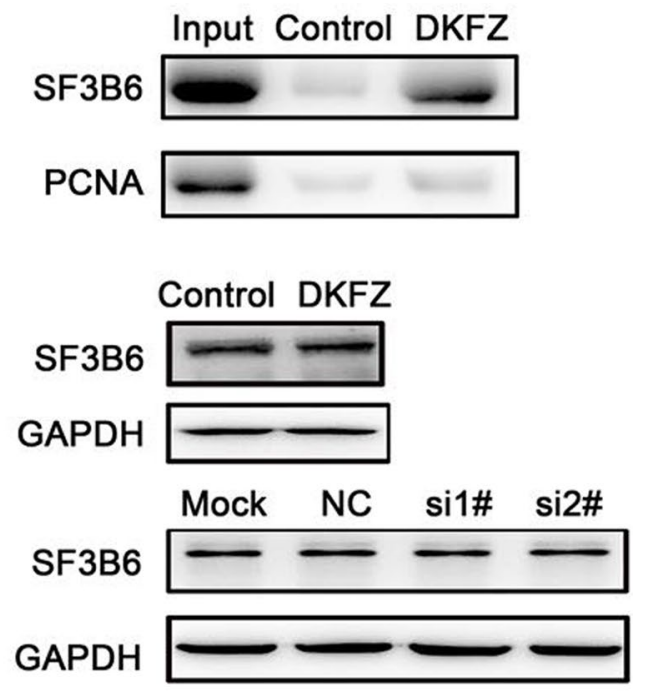
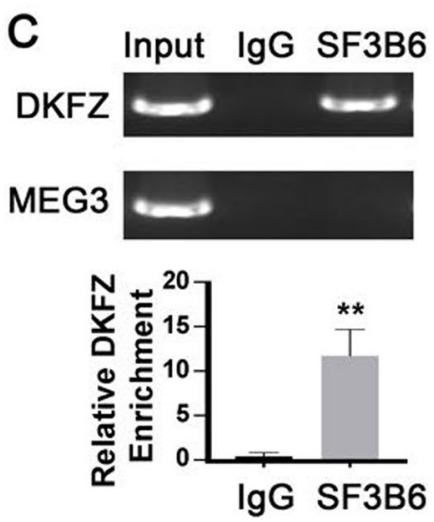

E IP:SF3B6 Control DKFZ
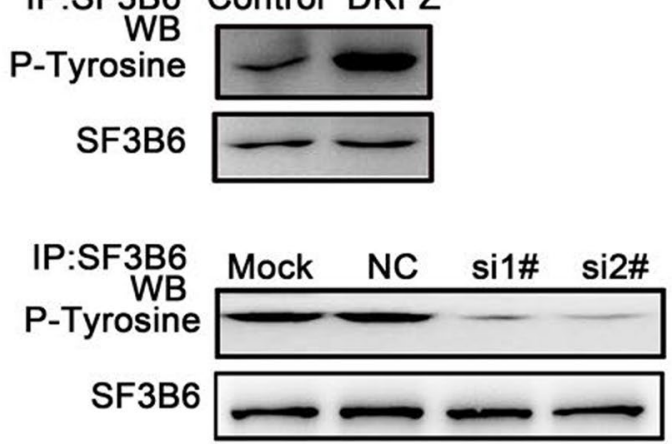

Fig. 5 SF3B6 serves as a DKFZp434J0226 (DKFZ)-binding protein. A RNA pull-down assay performed in the HEK293T cell lysates with biotin-labeled oligos. After pull-down, proteins were subjected to SDS-PAGE and stained by Coomassie brilliant blue. The band indicated by the arrow was subjected to mass spectrometry. B Western blotting analysis determined the specific interaction of sense DKFZ with SF3B6 protein, but not with PCNA protein (negative control). C RNA immunoprecipitation (RIP) of SF3B6 interaction with DKFZ in the HEK293T cells. RNA-protein complexes immunoprecipitated by anti-SF3B6 or control lgG were determined by RT-qPCR using specific primers for DKFZ or MEG3 (negative control). Data are shown as mean $\pm S D(n=4) ;{ }^{* *} P<0.01$. D Western blotting analysis of SF3B6 levels in the indicated DKFZ overexpression AsPC-1 cells or DKFZ knockdown MIAPaCa-2 cells. E Western blotting analysis of SF3B6 phosphorylation levels in the indicated DKFZ overexpression AsPC-1 cells or DKFZ knockdown MIAPaCa-2 cells. For SF3B6 phosphorylation detection, cell lysates were prepared and subjected to immunoprecipitation (IP) with anti-SF3B6 antibody, followed by immunoblotting analysis with the anti-phospho-tyrosine antibody

overexpressed or knockdown cells (Fig. 5D). As previous studies have reported the importance of phosphorylation in alternative splicing, we examined the level of SF3B6 phosphorylation in both overexpressed and knockdown cells and found that SF3B6 phosphorylation levels were significantly increased in DKFZp434J0226-overexpressed cells and decreased in DKFZp434J0226-knockdown cells (Fig. 5E).

\section{DKFZp434J0226 promotes translocation of SF3B6} from the cytoplasm to the nucleus and modulates alternative splicing

To identify the effect of DKFZp434J0226 on splicing factor SF3B6, we examined the expression of SF3B6 in the nucleus and cytoplasm of DKFZp434J0226overexpressed AsPC-1 cells using western blotting. DKFZp434J0226 overexpression promoted the translocation of SF3B6 from the cytoplasm to the nucleus (Fig. 6A). Furthermore, we performed immunofluorescence 
A

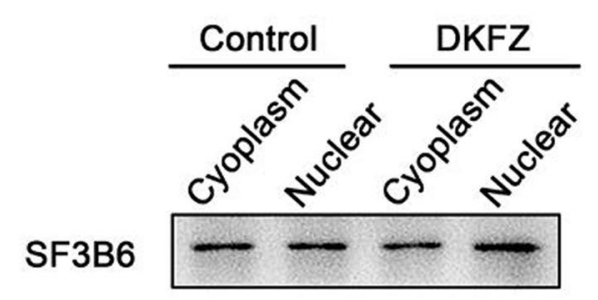

GAPDH

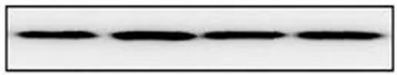

B
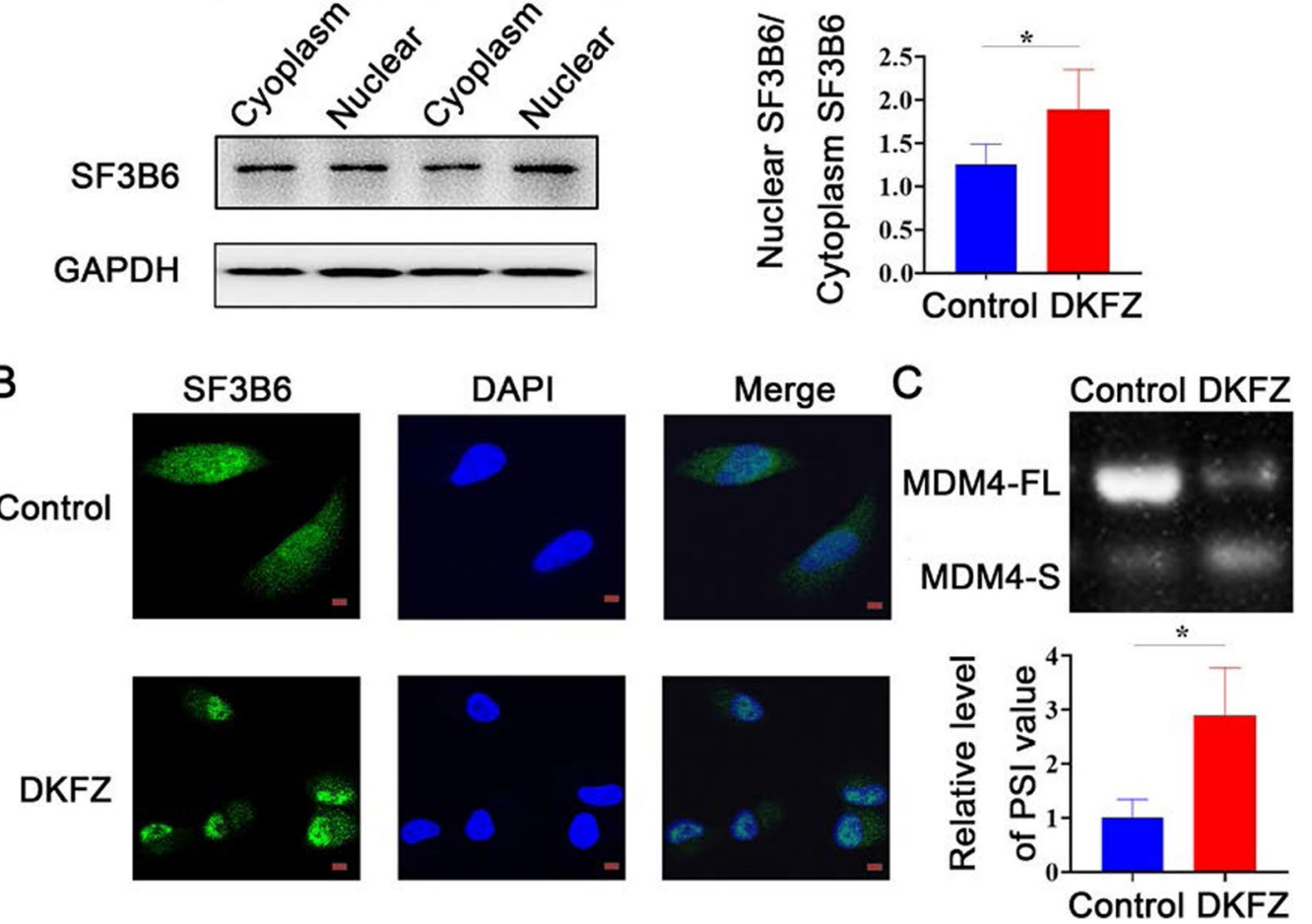

Fig. 6 DKFZp434J0226 (DKFZ) increases the nuclear localization of SF3B6. A Western analysis and quantification of nuclear and cytoplasmic SF3B6 in control and DKFZ-overexpressed AsPC-1 cells. Nuclear and cytoplasmic subcellular fractions were extracted as described in "Materials and methods" section. B Protein levels of SF3B6 in the nucleus and cytoplasm observed using confocal microscope. C DKFZ regulates alternative splicing of SF3B6 downstream MDM4. The alternative spliced transcripts (MDM4-FL, MDM4 full-length transcript; MDM4-S, MDM4 S transcript) in control and DKFZ-overexpressed AsPC-1 cells were verified by RT-qPCR. The percent spliced in index (PSI) was quantified for the alternative splicing events $(\mathrm{n}=5)$. A, C Data are shown as mean $\pm S D ;{ }^{*} P<0.05,{ }^{*} P<0.01$. Scale bars refer to $20 \mu \mathrm{m}$

analysis using DKFZp434J0226-overexpressed and control cells. In DKFZp434J0226-overexpression AsPC-1 cells, SF3B6 signals aggregated in the nucleus (Fig. 6B). Together, these results indicated that the lncRNA DKFZp434J0226 may contribute to the translocation of SF3B6 from the cytoplasm to the nucleus in PDAC cells.

To investigate the effect of DKFZp434J0226on alternative splicing, we analyzed the alternative splicing of the MDM4 transcript, which has been recently reported as an SF3B6 target mRNA (Siebring-van Olst et al. 2017). RT-qPCR indicated that DKFZp434J0226 overexpression promoted the expression of the MDM4-S transcript and decreased the expression of the MDM4-FL transcript in AsPC-1 cells (Fig. 6C). These results indicated a potential role of DKFZp434J0226 in modulating alternative splicing events.

\section{SF3B6 is required in DKFZp434J0226-induced cell proliferation and migration}

To study whether DKFZp434J0226 increases cell migration and proliferation via SF3B6, we knocked down SF3B6 in DKFZp434J0226-overexpressed AsPC-1 and CFPAC-1 cell lines. We found that DKFZ-induced cell proliferation was rescued by SF3B6 knockdown, as evidenced by the results of the cell growth curve assay (Fig. 7A and (Additional file 2: Fig. S2A), soft agar colony formation assay (Fig. 7B and (Additional file 2: Fig. S2B), and western blotting of PCNA (Fig. 7C and (Additional file 2: Fig. S2C). In addition, SF3B6 silencing inhibited DKFZp434J0226 overexpression-induced cell migration, as measured by migration invasion assays (Fig. 7D and (Additional file 2: Fig. S2D). Furthermore, SF3B6 silencing reduced DKFZp434J0226 overexpression-induced alternative splicing of MDM-4 (Fig. 7E and (Additional file 2: Fig. S2E). These results indicated that SF3B6 was necessary for DKFZp434J0226-induced cell growth and migration. 


\section{DKFZp434J0226 promotes tumor growth in vivo}

To examine the biological effect of DKFZp434J0226 in vivo, we subcutaneously injected AsPC-1 cells infected with control or DKFZp434J0226 lentiviruses into nude mice. DKFZp434J0226 overexpression significantly promoted tumor growth, assessed by tumor size (Fig. 8A, B) and weight (Fig. 8C). These results confirmed that DKFZp434J0226 promoted tumor growth and may have oncogenic functions in vivo. Next, we examined the phosphorylation of SF3B6 in mouse tumor tissues. Western blotting showed that the phosphorylation level of SF3B6 was greatly increased in the DKFZp434J0226 overexpression group (Fig. 8D). Furthermore, we examined the expression of MDM4 transcripts in tumor samples. An increase in the expression of the MDM4-S transcript was observed in DKFZp434J0226-overexpressed tumor tissues (Fig. 8E). Together, the results provided in vivo evidence that DKFZp434J0226 can contribute to SF3B6 phosphorylation and alternative splicing of SF3B6 downstream genes.

\section{Discussion}

Over the past decades, several studies have shown that ncRNAs have regulatory potential both in transcription and post-transcription and play important biological roles in human diseases (Mercer et al. 2009; Wilusz et al. 2009). Furthermore, lncRNAs have been shown to be associated with a spectrum of biological processes, such as modulation of alternative splicing, protein activity, and epigenetic regulation (Sana et al. 2012; Werner et al. 2017). In this study, we studied the profiles of lncRNA expression between PDAC tissues and adjacent normal tissues using human lncRNA/mRNA expression microarray analysis. The lncRNADKFZp434J0226 was found to be aberrantly increased in PDAC tissues, and increased DKFZp434J0226 expression was positively associated with poor prognosis and aggressive phenotypes in patients with PDAC. Furthermore, the study demonstrated that DKFZp434J0226 promotes the phosphorylation and translocation of SF3B6, an important splicing factor, and modulates the alternative splicing process in PDAC cells.

Using human lncRNA/mRNA expression microarray analysis, we identified 106 differentially expressed lncRNAs and 222 aberrantly expressed mRNAs in 33,045 lncRNAs and 30,215 coding transcripts, respectively. GO analysis suggested that the upregulated mRNAs mainly aggregated in the "spliceosome," the "metabolic pathway," and "glycosaminoglycan and keratan sulfate." These data are consistent with the viewpoint that PDAC is a disease of metabolic aberration and immune imbalance (Stolzenberg-Solomon et al. 2013; Matsuda et al. 2013; Sideras et al. 2013); glycosaminoglycan and keratan sulfate are important components of the extracellular matrix, which broadly participate in extracellular signal transduction and are closely associated with the metastasis and invasion of tumor cells (Shrimali et al. 2013; Heinemann et al. 2014). Aberrant expression of genes included in glycosaminoglycan and keratan sulfate biosynthesis in PDAC may provide insights into the molecular pathogenesis and may explain the highly aggressive behavior of PDAC.

The expression pattern of lncRNAs has been documented in different types of human malignant tumors (Gupta et al. 2010; Yang et al. 2011; Ji et al. 2003; Schmitt et al. 2016), but only a few studies have reported the roles of some specific lncRNAs in pancreatic cancer. Liu et al. (2014) reported that MALAT1 could be an independent predictor of disease-specific survival of PDAC (Tahira et al. 2011). They studied the role of intronic and intergenic lncRNAs in PDAC and found that loci harboring intronic lncRNAs were aberrantly expressed in PDAC metastases. We found thatDKFZp434J0226, a 1635-bp intergenic lncRNA located in the region of chromosome $19 \mathrm{q} 13.3$, is upregulated in PDAC. To date, only one study has reported the function of DKFZp434J0226; the results showed a possible association between DKFZp434J0226expression and prognosis of colorectal cancer (Zhao et al. 2018). In our study, highDKFZp434J0226 levels were positively correlated with tumor phenotypes such as tumor grading, TNM stage, and perineural invasion. Loss-and gain-offunction assays in vitro revealed that DKFZp434J0226 promoted cell migration, invasion, and cell proliferation in PDAC cells.

Recent studies have suggested that lncRNAs could regulate alternative splicing (Wang et al. 1998; Eto et al. 2010; Misteli et al. 1997). The main mechanisms can be categorized into three types: (i) lncRNAs interact with specific splicing factors, (ii) lncRNAs bind to pre-mRNA molecules, and (iii) lncRNAs affect chromatin remodeling. A subset of lncRNAs has been reported to bind splicing factors and affect their activity by (i) regulating their post-translational modification (such as phosphorylation) or (ii) modulating their interactions with other splicing factors (Tripathi et al. 2010). Analyses have revealed that phosphorylation of SF3B1, an important member of SF3b spliceosome, is essential for splicing (Wang et al. 1998). Phosphorylated SF3B1 has been reported in nuclear structures, whereas non-phosphorylated SF3B1 has been found in the nucleoplasm, suggesting that phosphorylation of SFB1 may play a vital role in pre-mRNA splicing on chromatin concomitant with transcription (Eto et al. 2010). In addition, SR proteins and some other snRNP proteins were found to be phosphorylated to form functional spliceosomes (Misteli et al. 1997). These findings indicate that phosphorylation 


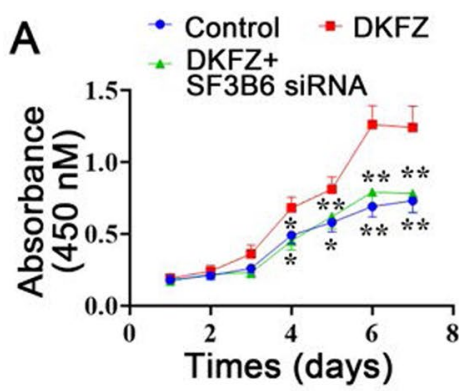

C
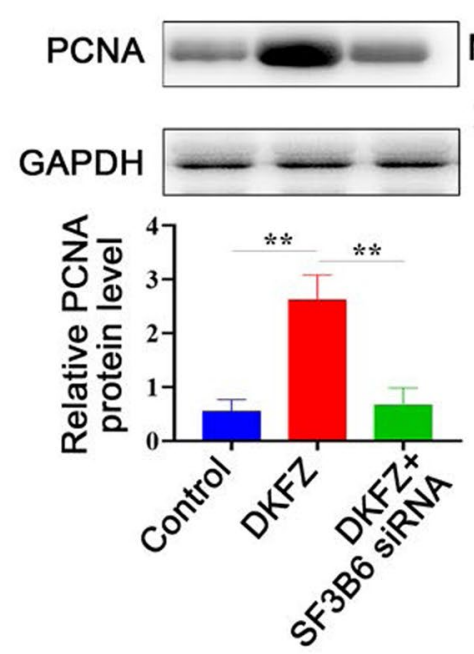

D

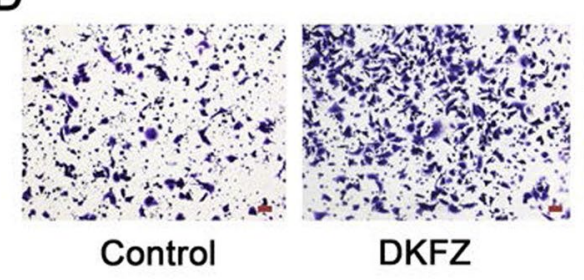

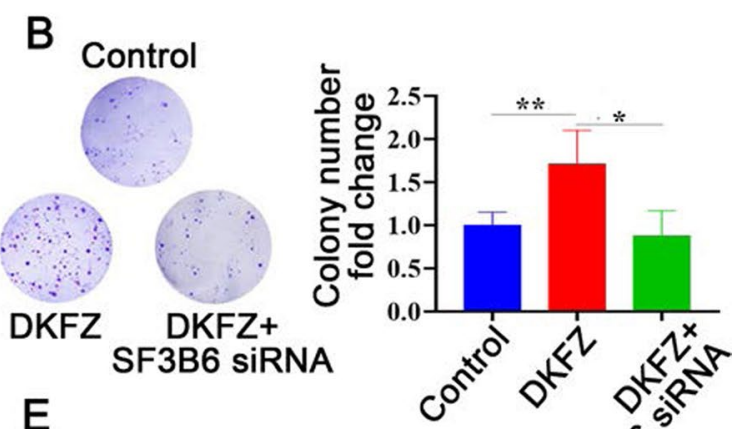

$\mathrm{E}$
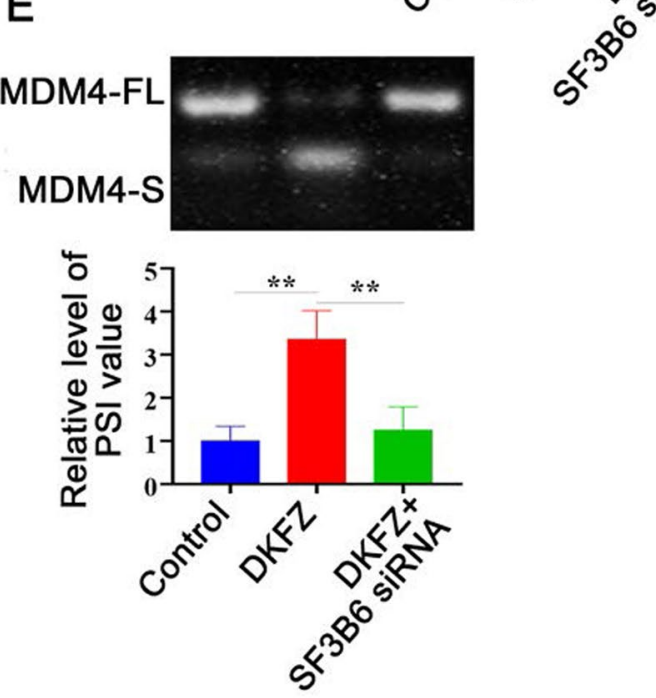
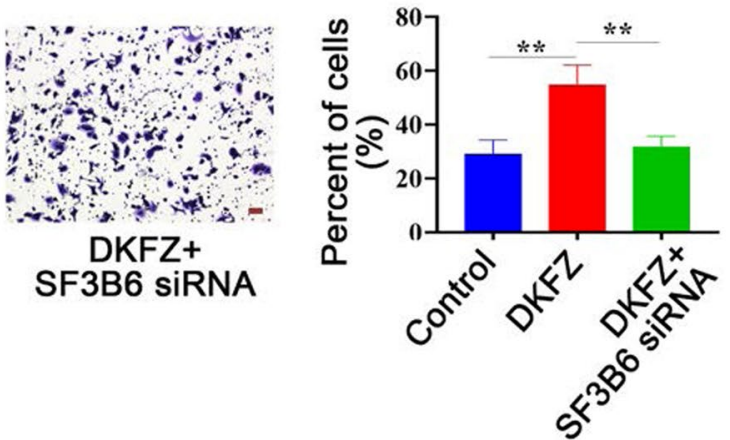

Fig. 7 SF3B6 is required in DKFZp434J0226 (DKFZ)-induced proliferation and migration. A-C Cell growth curves assay (A), soft agar colony formation assay (B), and western blotting of PCNA (C) demonstrating that SF3B6 knockdown rescues DKFZ-induced cell proliferation. D Migration assay demonstrating that SF3B6 knockdown rescues DKFZ-induced cell migration. E RT-qPCR demonstrating that SF3B6 knockdown rescues DKFZ-induced alternative splicing of MDM-4. A Data are shown as mean $\pm S D ; * P<0.05$ vs. Mock and N; ${ }^{* *} P<0.01$ vs. DKFZ. B-E Data are shown as mean $\pm S D ;{ }^{*} P<0.05,{ }^{*} P<0.01$. Scale bars refer to $100 \mu \mathrm{m}$

of some splicing factors might not only contribute to the assembly of the spliceosome but also to intranuclear transportation. Consistent with these studies, we found thatDKFZp434J0226 promotes the phosphorylation of the splicing factor SF3B6, elevates its nuclear translocation, and consequently regulates alternative splicing.
As a multiprotein complex component of the spliceosome, the splicing factor SF3B complex is necessary for branch site selection and recognition in the splicing process. It is made of seven proteins: SF3B6/p14, SF3B1/ SAP155, SF3B2/SAP145, SF3B3/SAP130, SF3B4/SAP49, SF3B5 and SF3B14b (Sun and Sun 2020). In the spliceosome, SF3B proteins in contact with pre-mRNA around 
A

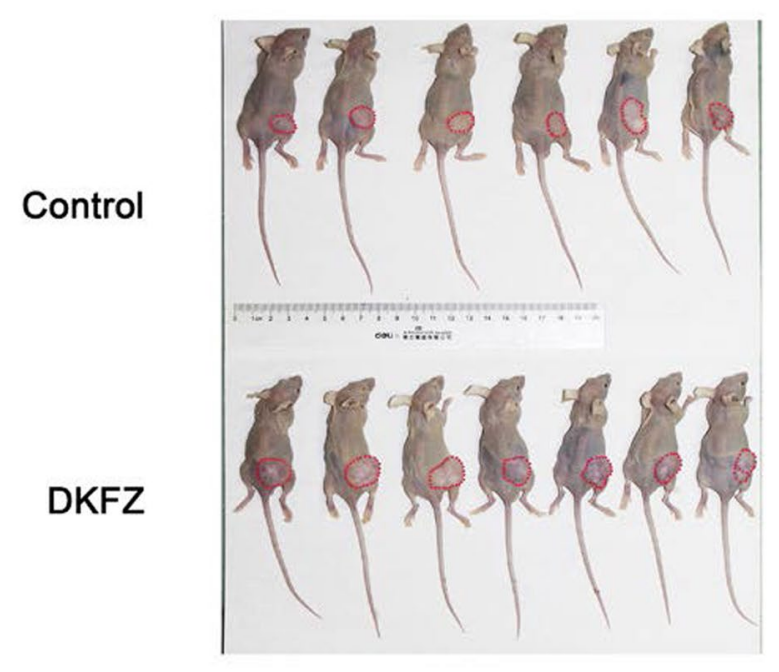

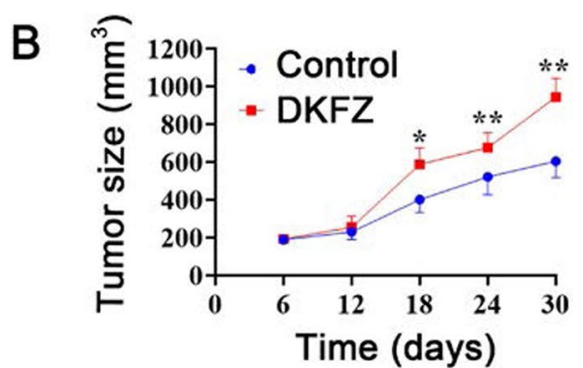

C

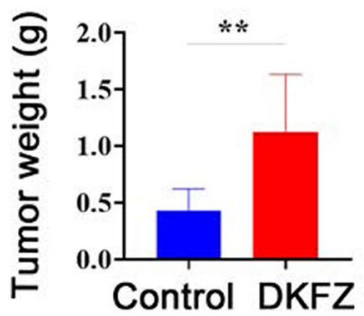

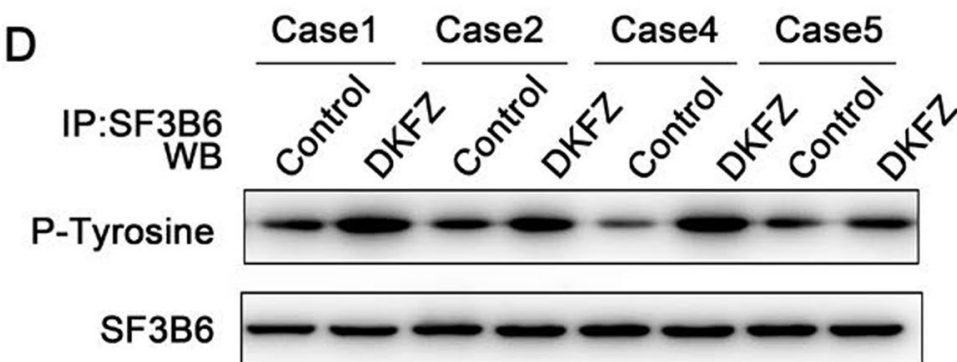

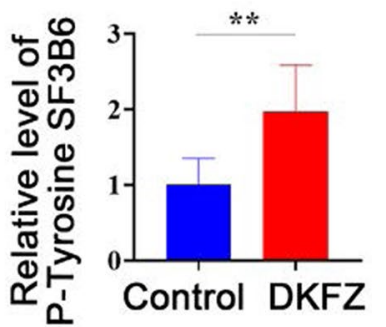

E
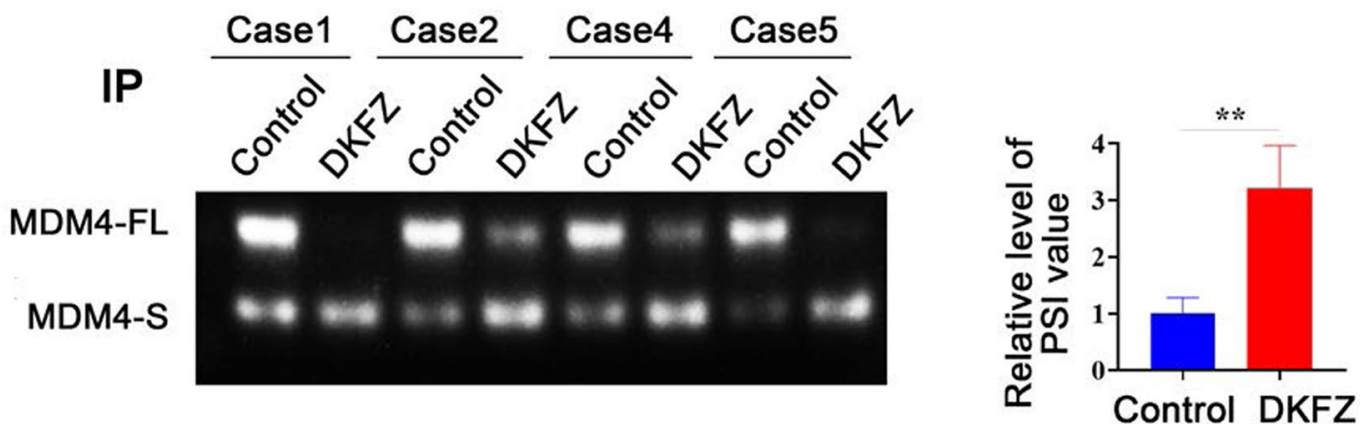

Fig. 8 DKFZp434J0226 (DKFZ) inhibits xenograft tumor growth. MiaPaCa-2 cells infected with control lentivirus (control, $n=6)$ and DKFZ lentivirus (DKFZ, $n=7$ ) were injected subcutaneously into nude mice. A Tumor size. B In vivo subcutaneous tumor growth curves. Data are shown as mean $\pm S D ;{ }^{*} P<0.05$ vs. Mock and NC; ${ }^{* *} P<0.01$ vs. control. C Total tumor weight of each group of mice. D Western blotting analysis and quantification of SF3B6 phosphorylation levels in indicated tumors $(n=4)$. E The alternative spliced transcripts (MDM4-FL, MDM4 full-length transcript; MDM4-S, MDM4 S transcript) in the indicated tumors verified by RT-qPCR. The percent spliced in index was quantified for the alternative splicing events $(n=4)$. C-E Data are shown as mean $\pm S D ;{ }^{*} P<0.05$, ${ }^{*} P<0.01$

the branch site strengthen the U2 snRNA/BS base-pairing interaction, thereby playing a vital role in branch site recognition and splicing. Among them, SF3B6 is located near the catalytic center, associated with the first step of the splicing reaction (Will et al. 2001; Spadaccini et al. 2006), indicating that SF3B6 plays a vital role in the early splicing process (Perea et al. 2016). Although SF3B6 plays a crucial role in alternative splicing, there 
are only a few studies on the target pre-mRNA of SF3B6. Recently, MDM4 was identified as a target pre-mRNA of SF3B6 (Siebring-van Olst et al. 2017). Its alternative splicing product, the MDM4-S transcript, encodes a truncated $\mathrm{Mdm} 4$ protein with the $\mathrm{N}$-terminal 114 amino acid p53-binding domain and C-terminal 26 aa residues (Rallapalli et al. 1999). Previous overexpression studies have shown that MDM4-S lacks an internal autoinhibitory sequence. Moreover, nuclear-localized MDM4-S can act as a strong p53 inhibitor; therefore, it likely functions as an oncogene (Rallapalli et al. 2003). We found that $D K$ FZp434J0226 increased the level of MDM4-S transcript, indicating a role of DKFZp434J0226 in the promotion of oncogene production by regulating alternative splicing.

\section{Conclusions}

Taken together, our results, for the first time, identified DKFZp434J0226 as an oncogenic IncRNA in PDAC. DKFZp434J0226 promotes oncogenesis of PDAC by interacting with SF3B6 and regulating alternative splicing.

\begin{abstract}
Abbreviations
IncRNA: Long noncoding RNA; PDAC: Pancreatic ductal adenocarcinoma; ncRNAs: Non-coding RNAs; pre-mRNA: Precursor mRNA; RT-qPCR: Quantitative real-time polymerase chain reaction; GO: Gene ontology; CNC: Coding-noncoding gene co-expression; PCR: Polymerase chain reaction; PBS: Phosphatebuffered saline; SDS-PAGE: Sodium dodecyl sulphate-polyacrylamide gel electrophoresis; ANOVA: Analysis of variance; SD: Standard deviation; T/N: Tumor/normal; HOX: Human Homeobox transcription factor; HPDE: Human pancreatic ductal epithelial; OS: Overall survival; TTP: Time to progression; CCK-8: Cell counting kit-8; RAP-MS: RNA pull-down assay combined with mass spectrometry; DE: Differentially expressed genes; RIP: RNA immunoprecipitation; IP: Immunoprecipitation; PSI: Percent spliced in index.
\end{abstract}

\section{Supplementary Information}

The online version contains supplementary material available at https://doi. org/10.1186/s10020-021-00347-7.

Additional file 1: Table S1. Primer sequences used in this study. Table S2. Clinical characteristics of 6 patients with PDAC for microarray. Table S3. 128 differentially expressed IncRNAs $(\geq 2$-fold, $P<0.05$ ) between six PDAC samples and paired nontumor samples. Table S4. 281 HOX IncRNAs detected in PDAC. Table S5. 2341 Rinn IncRNAs detected in PDAC. Table S6. 1133 Enhancer IncRNAs detected in PDAC. Table S7. 222 differentially expressed mRNAs $(\geq 2$-fold, $\mathrm{P}<0.05$ ) between six PDAC samples and paired nontumor samples. Table $\mathbf{S} 8$. Clinical characteristics in 109 patients with pancreatic cancer. Table S9. Correlation between DKFZp434J0226 and clinical characteristics. Table S10. Univariate analysis of factors associated with survival and recurrence.

Additional file 2: Figure S1. DKFZp434J0226 (DKFZ) promotes PDAC cell proliferation and migration. (A, B) Verification of DKFZ knockdown (A) and DKFZ overexpression (B) efficiency in PANC-1 and CFPAC-1 cells $(n=3)$. Data are shown as mean $\pm S D ;{ }^{*} P<0.05,{ }^{* *} P<0.01$. (C) Cell growth curves of lipofectamine-treated PANC-1 (Mock) cells, negative siRNA-transfected PANC-1 (NC) cells, and two DKFZ siRNA-transfected PANC-1 (si1 and si2; $\mathrm{n}=4$ ). Data are shown as mean $\pm \mathrm{SD} ;{ }^{*} P<0.05$ vs. Mock and $N C ;{ }^{* *} P<0.01$ vs. Mock and NC. (D) Cell growth curves of control lentivirus-infected CFPAC-1 cells (control) and DKFZ lentivirus-infected CFPAC-1 cells (DKFZ) $(n=4)$. Data are shown as mean $\pm S D ;{ }^{*} P<0.05$ vs. Mock and NC; ${ }^{* *} P<0.01$ vs. Mock and NC. (E) Western blotting analysis of PCNA expression in the indicated PDAC cells. (F-I) Wound healing ( $F, G)$, migration $(H)$ assays and soft agar colony formation assay (I) using the indicated PDAC cells. $(n=4)$. (F-I) Data are shown as mean $\pm S D ;{ }^{*} P<0.05,{ }^{* *} P<0.01$. Scale bars refer to $100 \mu \mathrm{m}$. Figure S2. (A-C) Cell growth curves assay (A), soft agar colony formation assay (B), and western blotting of PCNA (C) demonstrating that SF3B6 knockdown rescues DKFZ-induced cell proliferation in CFPAC-1 cells. (D) Migration assay demonstrating that SF3B6 knockdown rescues DKFZ-induced cell migration in CFPAC-1 cells. (E) RT-qPCR demonstrating that SF3B6 knockdown rescues DKFZ-induced alternative splicing of MDM-4. (A) Data are shown as mean $\pm S D ;{ }^{*} P<0.05$ vs. DKFZ; ${ }^{* *} P<0.01$ vs. DKFZ. (B-E) Data are shown as mean $\pm S D ;{ }^{*} P<0.05,{ }^{* *} P<0.01$. Scale bars refer to $100 \mu \mathrm{m}$.

\section{Acknowledgements}

Thanks to all members of our team for critical input and suggestions.

\section{Authors' contributions}

$J \mathrm{~L}, \mathrm{XQ}, \mathrm{SZ}, \mathrm{RX}$ and $\mathrm{HT}$ performed the experiments and wrote the manuscript, QJ and DL participated in the cell experiments and data analysis. WT, YZ, SC and DJ provided technical supports. XQ, SZ and RX conceived and designed the experiments. All authors read and approved the final manuscript.

\section{Funding}

This study was supported by funds from the Shanghai Public Health Clinic Center (SPHCC-2018-2) and the National Natural Science Foundation of China (81871934, 81770137, 81572308, 81573423, 81772615, 81972294).

\section{Availability of data and materials}

The datasets used and/or analyzed during the current study are available from the corresponding author on reasonable request.

\section{Declarations}

\section{Ethics approval and consent to participate}

Ethical approval for human subjects was obtained from the research ethics committee of Zhongshan Hospital (Y2015-057), and written informed consent was obtained from each patient.

\section{Consent for publication}

We would like to submit the enclosed manuscript entitled "The long noncoding RNA DKFZp434J0226 regulates the alternative splicing process through phosphorylation of SF3B6 in PDAC", which we wish to be considered for publication in Molecular Medicine.

\section{Competing interests}

The author reports no conflicts of interest in this work.

Received: 16 April 2021 Accepted: 29 July 2021

Published online: 28 August 2021

\section{References}

Bao B, Wang Z, Ali S, et al. Metformin inhibits cell proliferation, migration and invasion by attenuating CSC function mediated by deregulating miRNAs in pancreatic cancer cells. Cancer Prev Res. 2012;5(3):355-64. https://doi. org/10.1038/srep03098.

Eto K, Sonoda Y, Jin Y, Abe S. Phosphorylated SAP155, the spliceosomal component, is localized to chromatin in postnatal mouse testes. Biochem Biophys Res Commun. 2010;393(4):577-81. https://doi.org/10.1016/j. bbrc.2010.02.014.

Gibb EA, Vucic EA, Enfield KS, Stewart GL, Lonergan KM, Kennett JY, BeckerSantos DD, MacAulay CE, Lam S, Brown CJ, Lamet WL. Human cancer long non-coding RNA transcriptomes. PLoS ONE. 2011;6(10):e25915. https://doi.org/10.1371/journal.pone.0025915. 
Gupta RA, Shah N, Wang KC, Kim J, Horlings HM, Wong DJ, Tsai MC, Hung T, Argani P, Rinn JL, Wang Y, Brzoska P, Kong B, Li R, West RB, van de Vijver MJ, Sukumar S, Chang HY. Long non-coding RNA HOTAIR reprograms chromatin state to promote cancer metastasis. Nature. 2010;464(7291):10716. https://doi.org/10.1038/nature08975.

Heinemann V, Reni M, Ychou M, Richel DJ, Macarulla T, Ducreux M. Tumourstroma interactions in pancreatic ductal adenocarcinoma: rationale and current evidence for new therapeutic strategies. Cancer Treat Rev. 2014;40(1):118-28. https://doi.org/10.1016/j.ctrv.2013.04.004.

Hu S, Wang X, Shan G. Insertion of an Alu element in a IncRNA leads to primate-specific modulation of alternative splicing. Nat Struct Mol Biol. 2016;23(11):1011-9. https://doi.org/10.1038/nsmb.3302.

Ji P, Diederichs S, Wang W, Böing S, Metzger R, Schneider PM, Tidow N, Brandt B, Buerger H, Bulk E, Thomas M, Berdel WE, Serve H, Müller-Tidow C. MALAT-1, a novel noncoding RNA, and thymosin beta 4 predict metastasis and survival in early-stage non-small cell lung cancer. Oncogene. 2003;22(39):8031-41. https://doi.org/10.1038/sj.onc.1206928.

Li D, Xie K, Wolff R, Abbruzzese JL. Pancreatic cancer. Lancet. 2004;363(9414):1049-57. https://doi.org/10.1016/S0140-6736(04)15841-8.

Liu Y, Cao W, Zhang B, Liu YQ, Wang ZY, Wu YP, Yu XJ, Zhang XD, Ming PH, Zhou $G B$, Huang L. The natural compound magnolol inhibits invasion and exhibits potential in human breast cancer therapy. Sci Rep. 2013;3:3098. https://doi.org/10.1038/srep03098.

Liu JH, Chen G, Dang YW, Li CJ, Luo DZ. Expression and prognostic significance of IncRNA MALAT1 in pancreatic cancer tissues. Asian Pac J Cancer Prev. 2014;15(7):2971-7. https://doi.org/10.7314/apjcp.2014.15.7.2971.

Matsuda M, Shimomura I. Increased oxidative stress in obesity: implications for metabolic syndrome, diabetes, hypertension, dyslipidemia, atherosclerosis, and cancer. Obes Res Clin Pract. 2013;7(5):e330-41. https://doi.org/10. 1016/j.orcp.2013.05.004

Mercer TR, Dinger ME, Mattick JS. Long non-coding RNAs: insights into functions. Nat Rev. 2009;10(3):155-9. https://doi.org/10.1038/nrg2521.

Misteli T, Spector DL. Protein phosphorylation and the nuclear organization of pre-mRNA splicing. Trends Cell Biol. 1997;7(4):135-8. https://doi.org/10. 1016/S0962-8924(96)20043-1.

Omura N, Goggins M. Epigenetics and epigenetic alterations in pancreatic cancer. Int J Clin Exp Pathol. 2009;2(4):310-26. https://doi.org/10.3109/ 14992020903085735.

Ørom UA, Derrien T, Beringer M, Gumireddy K, Gardini A, Bussotti G, Lai F, Zytnicki M, Notredame C, Huang Q, Guigo R, Shiekhattar R. Long noncoding RNAs with enhancer-like function in human cells. Cell. 2010;143(1):46-58. https://doi.org/10.1016/j.cell.2010.09.001.

Perea W, Schroeder KT, Bryant AN, Greenbaum NL. Interaction between the spliceosomal pre-mRNA branch site and U2 snRNP protein p14. Biochemistry. 2016;55(4):629-32. https://doi.org/10.1021/acs.biochem.5b01036.

Ponting CP, Oliver PL, Reik W. Evolution and functions of long noncoding RNAs. Cell. 2009;136(4):629-41. https://doi.org/10.1016/j.cell.2009.02.006.

Rallapalli R, Strachan G, Cho B, Mercer WE, Hall DJ. A novel MDMX transcript expressed in a variety of transformed cell lines encodes a truncated protein with potent p53 repressive activity. J Biol Chem. 1999;274(12):8299308. https://doi.org/10.1074/jbc.274.12.8299.

Rallapalli R, Strachan G, Tuan RS, Hall DJ. Identification of a domain within MDMX-S that is responsible for its high affinity interaction with p53 and high-level expression in mammalian cells. J Cell Biochem. 2003;89(3):56375. https://doi.org/10.1002/jcb.10535.

Rinn JL, Kertesz M, Wang JK, Squazzo SL, Xu X, Brugmann SA, Goodnough LH, Helms JA, Farnham PJ, Segal E, Chang HY. Functional demarcation of active and silent chromatin domains in human HOX loci by noncoding RNAs. Cell. 2007;129(7):1311-23. https://doi.org/10.1016/j.cell.2007.05. 022.

Sana J, Faltejskova P, Svoboda M, Slaby O. Novel classes of non-coding RNAs and cancer. J TransI Med. 2012;10:103. https://doi.org/10.1186/ 1479-5876-10-103.

Schmidt LH, Spieker T, Koschmieder S, Schäffers S, Humberg J, Jungen D, Bulk E, Hascher A, Wittmer D, Marra A, Hillejan L, Wiebe K, Berdel WE, Wiewrodt $R$, Muller-Tidow $C$. The long noncoding MALAT-1 RNA indicates a poor prognosis in non-small cell lung cancer and induces migration and tumor growth. J Thorac Oncol. 2011;6(12):1984-92. https://doi.org/10. 1097/JTO.0b013e3182307eac.

Schmitt AM, Chang HY. Long noncoding RNAs in cancer pathways. Cancer Cell. 2016;29(4):452-63. https://doi.org/10.1016/j.ccell.2016.03.010.

Shrimali D, Shanmugam MK, Kumar AP, Zhang J, Tan BK, Ahn KS, Sethi G. Targeted abrogation of diverse signal transduction cascades by emodin for the treatment of inflammatory disorders and cancer. Cancer Lett. 2013;341(2):139-49. https://doi.org/10.1016/j.canlet.2013.08.023.

Sideras K, Braat H, Kwekkeboom J, van Eijck CH, Peppelenbosch MP, Sleijfer $\mathrm{S}$, Bruno $\mathrm{M}$. Role of the immune system in pancreatic cancer progression and immune modulating treatment strategies. Cancer Treat Rev. 2013;40(4):513-22. https://doi.org/10.1016/j.ctrv.2013.11.005.

Siebring-van Olst E, Blijlevens M, de Menezes RX, van der Meulen-Muileman $\mathbb{H}$, Smit EF, van Beusechem VW. A genome-wide siRNA screen for regulators of tumor suppressor p53 activity in human non-small cell lung cancer cells identifies components of the RNA splicing machinery as targets for anticancer treatment. Mol Oncol. 2017;11(5):534-51. https://doi.org/ 10.1002/1878-0261.12052.

Siegel RL, Miller KD, Jemal A. Cancer statistics, 2020. CA Cancer J Clin. 2020;70(1):7-30. https://doi.org/10.3322/caac.21442.

Simard EP, Ward EM, Siegel R, Jemal A. Cancers with increasing incidence trends in the United States: 1999 through 2008. CA Cancer J Clin. 2014. https://doi.org/10.3322/caac.20141.

Spadaccini R, Reidt U, Dybkov O, Will C, Frank R, Stier G, Corsini L, Wahl MC, Lührmann R, Sattler M. Biochemical and NMR analyses of an SF3b155p14-U2AF-RNA interaction network involved in branch point definition during pre-mRNA splicing. RNA. 2006;12(3):410-25. https://doi.org/10. 1261/rna.2271406.

Stolzenberg-Solomon RZ, Schairer C, Moore S, Hollenbeck A, Silverman DT. Lifetime adiposity and risk of pancreatic cancer in the NIH-AARP Diet and Health Study cohort. Am J Clin Nutr. 2013;98(4):1057-65. https://doi.org/ 10.3945/ajen.113.058123.

Sun C. The SF3b complex: splicing and beyond. Cell Mol Life Sci. 2020;77(18):3583-95. https://doi.org/10.1007/s00018-020-03493-z.

Tahira AC, Kubrusly MS, Faria MF, Dazzani B, Fonseca RS, Maracaja-Coutinho V, Verjovski-Almeida S, Machado MC, Reis EM. Long noncoding intronic RNAs are differentially expressed in primary and metastatic pancreatic cancer. Mol Cancer. 2011;10:141. https://doi.org/10.1186/ 1476-4598-10-141.

Tripathi V, Ellis JD, Shen Z, Song DY, Pan Q, Watt AT, Freier SM, Bennett CF, Sharma A, Bubulya PA, Blencowe BJ, Prasanth SG, Prasanth KV. The nuclear-retained noncoding RNA MALAT1 regulates alternative splicing by modulating SR splicing factor phosphorylation. Mol Cell. 2010;39(6):925-38. https://doi.org/10.1016/j.molcel.2010.08.011.

Verma A, Wang H, Manavathi B, Fok JY, Mann AP, Kumar R, Mehta K. Increased expression of tissue transglutaminase in pancreatic ductal adenocarcinoma and its implications in drug resistance and metastasis. Cancer Res. 2006;66(21):10525-33. https://doi.org/10.1158/0008-5472.CAN-06-2387.

Wang KC, Chang HY. Molecular mechanisms of long noncoding RNAs. Mol Cell. 2011;43(6):904-14. https://doi.org/10.1016/j.molcel.2011.08.018.

Wang C, Chua K, Seghezzi W, Lees E, Gozani O, Reed R. Phosphorylation of spliceosomal protein SAP 155 coupled with splicing catalysis. Genes Dev. 1998;12(10):1409-14. https://doi.org/10.1101/gad.12.10.1409.

Wapinski O, Chang HY. Long noncoding RNAs and human disease. Trends Cell Biol. 2011;21(6):354-61. https://doi.org/10.1016/j.tcb.2011.04.001.

Wei Y, Jiang J, Liu D, Zhou J, Chen X, Zhang S, Zong H, Yun X, Gu J. Cdc34mediated degradation of ATF5 is blocked by cisplatin. J Biol Chem. 2008;283(27):18773-81. https://doi.org/10.1074/jbc.M707879200.

Werner MS, Sullivan MA, Shah RN, Nadadur RD, Grzybowski AT, Galat V, Moskowitz IP, Ruthenburg AJ. Chromatin-enriched IncRNAs can act as cell-type specific activators of proximal gene transcription. Nat Struct Mol Biol. 2017;24(7):596-603. https://doi.org/10.1038/nsmb.3424.

Will CL, Schneider C, MacMillan AM, Katopodis NF, Neubauer G, Wilm M, Lührmann R, Query CC. A novel U2 and U11/U12 snRNP protein that 
associates with the pre-mRNA branch site. EMBO J. 2001;20(16):4536-46 https://doi.org/10.1093/emboj/20.16.4536.

Wilusz JE, Sunwoo H, Spector DL. Long noncoding RNAs: functional surprises from the RNA world. Genes Dev. 2009;23(13):1494-504. https://doi.org/ 10.1101/gad.1800909.

Yang F, Zhang L, Huo XS, Yuan JH, Xu D, Yuan SX, Zhu N, Zhou WP, Yang GS, Wang YZ, Shang JL, Gao CF, Zhang FR, Wang F, Sun SH. Long noncoding RNA high expression in hepatocellular carcinoma facilitates tumor growth through enhancer of zeste homolog 2 in humans. Hepatology. 2011;54(5):1679-89. https://doi.org/10.1002/hep.24563.

Yokoi A, Kotake Y, Takahashi K, Kadowaki T, Matsumoto Y, Minoshima Y, Sugi $\mathrm{NH}$, Sagane K, Hamaguchi M, Iwata M, Mizui Y. Biological validation that SF3b is a target of the antitumor macrolide pladienolide. FEBS J. 2011;278(24):4870-80. https://doi.org/10.1111/j.1742-4658.2011.08387.x.
Zhang L, Yang Z, Trottier J, Barbier O, Wang L. Long noncoding RNA MEG3 induces cholestatic liver injury by interaction with PTBP1 to facilitate shp mRNA decay. Hepatology. 2017;65(2):604-15. https://doi.org/10.1002/ hep.28882.

Zhao J, Xu J, Shang AQ, Zhang RA. Six-LncRNA. Expression signature associated with prognosis of colorectal cancer patients. Cell Physiol Biochem. 2018;50(5):1882-90. https://doi.org/10.1159/000494868.

\section{Publisher's Note}

Springer Nature remains neutral with regard to jurisdictional claims in published maps and institutional affiliations.
Ready to submit your research? Choose BMC and benefit from:

- fast, convenient online submission

- thorough peer review by experienced researchers in your field

- rapid publication on acceptance

- support for research data, including large and complex data types

- gold Open Access which fosters wider collaboration and increased citations

- maximum visibility for your research: over $100 \mathrm{M}$ website views per year

At BMC, research is always in progress.

Learn more biomedcentral.com/submissions 